\title{
Effect of Er-Rich Precipitates on Microstructure and Electrochemical Behavior of the Al-5Zn-0.03In Alloy
}

\author{
Muzhi Yu ${ }^{1}{ }^{(}$, Jin Cui $^{1}$, Zhichao Tang $\left.{ }^{1}{ }^{(}\right)$, Zinan Shen ${ }^{1}$, Xiaoyang Chen ${ }^{1}$, Zhengbing $X u^{1,2, *}$ and \\ Jianmin Zeng ${ }^{2, *}$
}

1 Key Laboratory of Nonferrous Materials and New Processing Technology, School of Resources, Environment and Materials, Guangxi University, Nanning 530004, China; 1915391048@st.gxu.edu.cn (M.Y.); 2015301016@st.gxu.edu.cn (J.C.); 2015301066@st.gxu.edu.cn (Z.T.); long1992sz@163.com (Z.S.); xiaoyang_chen@163.com (X.C.)

2 Center of Ecological Collaborative Innovation for Aluminum Industry in Guangxi, Nanning 530004, China

* Correspondence: xuzhb@gxu.edu.cn (Z.X.); zjmg@gxu.edu.cn (J.Z.)

check for updates

Citation: Yu, M.; Cui, J.; Tang, Z.; Shen, Z.; Chen, X.; Xu, Z.; Zeng, J. Effect of Er-Rich Precipitates on Microstructure and Electrochemical Behavior of the Al-5Zn-0.03In Alloy. Metals 2022, 12, 131. https://doi.org/ $10.3390 /$ met12010131

Academic Editors: Alexander Ivanovich Zaitsev, David M. Bastidas and Wislei Riuper Osório

Received: 29 November 2021

Accepted: 6 January 2022

Published: 10 January 2022

Publisher's Note: MDPI stays neutral with regard to jurisdictional claims in published maps and institutional affiliations.

Copyright: (C) 2022 by the authors. Licensee MDPI, Basel, Switzerland. This article is an open access article distributed under the terms and conditions of the Creative Commons Attribution (CC BY) license (https:// creativecommons.org/licenses/by/ $4.0 /)$.

\begin{abstract}
The effect of Er-rich precipitates on microstructure and electrochemical behavior of the $\mathrm{Al}-\mathrm{Zn}$-In anode alloy is investigated. The results showed that with the increase in Er content, the microstructure was refined, the amount of interdendritic precipitates gradually increased, and the morphology changed from discontinuous to continuous network gradually. With the addition of Er element, the self-corrosion potential of the Al-5Zn-0.03In- $x$ Er alloy moved positively, the selfcorrosion current density decreased, and the corrosion resistance increased. When the Er content was less than $1 \mathrm{wt} . \%$, the addition of Er improved the dissolution state of the Al-5Zn-0.03In- $x$ Er alloy, and increased the current efficiency of the Al-5Zn-0.03In- $x$ Er alloy. When the Er content was more than $1 \mathrm{wt} . \%$, the current efficiency was reduced. The major precipitate of the alloy was $\mathrm{Al}_{3} \mathrm{Er}$. According to the element composition of $\mathrm{Al}_{3} \mathrm{Er}$ in the $\mathrm{Al}-\mathrm{Zn}$-In-Er alloy, the simulated-segregated-phase alloy was melted to explain the effect of $\mathrm{Al}_{3} \mathrm{Er}$ segregation on the electrochemical behavior of alloys, and the polarization curve and AC impedance spectrum of the simulated-segregated-phase alloy and the $\mathrm{Al}-\mathrm{Zn}-\mathrm{In}$ alloy were measured. The results showed that $\mathrm{Al}_{3} \mathrm{Er}$ was an anodic segregation phase in the Al-Zn-In-Er alloy, and the preferential dissolution of the segregation phase would occur in the alloy, but the $\mathrm{Al}_{3} \mathrm{Er}$ phase itself was passivated in the dissolution process, which inhibited the further activation of the dissolution reaction of the Al-Zn-In-Er alloy to a certain extent.
\end{abstract}

Keywords: Al-Zn-In-Er alloy; Er-rich precipitates; microstructure; electrochemical behavior; grain refinement

\section{Introduction}

The sacrificial anode protection method is a relatively mature electrochemical protection method, which has the advantages of simple equipment, convenient installation, low maintenance difficulty, long service life, low cost, and so on. It has been widely used in the field of industrial anticorrosion [1-5]. Due to the advantages of negative potential, large capacitance, and low price, aluminum has developed rapidly as a sacrificial anode material [6-8]. However, aluminum will form a dense passivation film on the surface in neutral medium, resulting in passivation [9]. By adding active elements, such as zinc and indium, the aluminum-based sacrificial anode alloy is melted, which is more successful in engineering application $[10,11]$. The Al-Zn-In series anode alloy has high current efficiency and good comprehensive performance, but its surface dissolution uniformity is poor, and the electrochemical performance still needs to be improved [12].

Microalloying is an important way to tap the potential and improve the properties of alloys. Owing to the inner electrons of rare earth elements are in an unsaturated state, they have many unique properties [13]. Adding rare earth elements to aluminum alloys can effectively improve the microstructure and comprehensive properties of the alloys [14-20]. 
It has been documented that the addition of La and Ce to Al-based anode alloys can refine the grains, improve the uneven corrosion, and enhance the electrochemical properties of the alloys [21-23].

Studies have shown that the as-cast grain size can be significantly refined by adding Er element to aluminum alloy, and nano-sized $\mathrm{Al}_{3} \mathrm{Er}$ particles can pin dislocations and sub-grain boundaries, hinder the movement of dislocations, and inhibit the recrystallization process, which can improve the strength and recrystallization temperature of aluminum alloys [13,24]. Vo, N.Q. et al. [19] found that using 0.005 at\% Er instead of the more expensive Sc can maintain higher room temperature strength and significantly improve high temperature creep resistance when studying the effect of $\mathrm{Si}, \mathrm{Zr}$, and Er microalloying on the Al-Sc alloy. Xinwei She [25] studied the effect of Er on the microstructure and properties of aluminum alloy with a large width thickness ratio. The results showed that the grain size can be refined by adding Er, and the refining effect is related to the content of Er, the refining effect is the best when the Er content is $0.4 \%$.

The properties and microstructure of aluminum alloy can be improved by adding other elements [26], but the solubility of most alloy elements in pure aluminum is limited and cannot be dissolved indefinitely, which leads to serious microstructure segregation. Therefore, there are usually two existing forms of alloy elements in aluminum alloy: one is a solid solution in the $\alpha-\mathrm{Al}$ matrix, and the other is in the form of segregated phase. Venugopal [27] believed that, in Al-Zn-In alloys, due to the precipitation of a large number of segregated phases at the grain boundaries, the alloy matrix is preferentially dissolved along the grain boundaries. Salinas et al. [28] found that the structure of aluminum alloys with $\mathrm{Zn} \leq 5 \mathrm{wt}$ \% is composed of a solid solution matrix and interdendritic compounds, and the interdendritic compound region is the initiation region of alloy dissolution, which is easy to cause alloy self-corrosion and the loss of current efficiency.

Our previous work $[29,30]$ found that the grainsize of the Al-5Zn-0.03In- $x$ Er alloy was refined when the Er content was lower than 4 wt.\%. In view of this, the samples of Al-5Zn$0.03 \mathrm{In}-x$ Er alloy with an Er content of $0.5 \mathrm{wt} . \%, 1 \mathrm{wt} . \%$, and $4 \mathrm{wt}$.\% were prepared to study the effects of Er content and $\mathrm{Al}_{3}$ Er precipitates on the microstructure and electrochemical properties of the alloy.

\section{Materials and Methods}

\subsection{Preparation of Al-Zn-In-Er Alloy}

Al-Zn (20 wt.\% Zn), Al-Er (10 wt.\% Er), and Al-In (1 wt.\% In) master alloys were melted in WKDHL-II non-consumable vacuum arc furnace. Al-Zn-In-Er alloys were melted with pure aluminum and the above master alloys in resistance furnace with the standard burden of $300 \mathrm{~g}$ per furnace. The chemical composition of the experimental alloy is shown in Table 1.

Table 1. Chemical composition tested alloys (wt.\%).

\begin{tabular}{ccccc}
\hline Alloy & Er & Zn & In & Al \\
\hline $1 \#$ & 0 & 5 & 0.03 & Balance \\
$2 \#$ & 0.5 & 5 & 0.03 & Balance \\
$3 \#$ & 1 & 5 & 0.03 & Balance \\
$4 \#$ & 4 & 5 & 0.03 & Balance \\
\hline
\end{tabular}

\subsection{Preparation of the $\mathrm{Al}_{3}$ Er-Simulated Alloy}

Pure aluminum and pure erbium are weighed at the standard of $3.5 \mathrm{~g}$ per furnace according to the mass percentage of $\mathrm{Al}_{3} \mathrm{Er}$. $\mathrm{A} \mathrm{Al} \mathrm{Al}_{3} \mathrm{Er}$-simulated precipitates alloy was melted in a WKDHL-II non-consumable vacuum arc furnace. Because the copper crucible used in the arc furnace is cooled by circulating water, and the sample cooling rate is very fast, it is necessary to carry out homogenization annealing in muffle furnace after vacuum packing, whereby the annealing temperature is $800^{\circ} \mathrm{C}$ and the holding time is 30 days. 


\subsection{Microstructure Observation and Electrochemical Performance Test of the Alloy}

The microstructure of the alloy was observed by a Leica DM2700P polarized light microscope (Leica, Weltzar, Germany), and the distribution and morphology of the segregation phase were observed by Hitachi SU8220 scanning electron microscope (Hitachi, Tokyo, Japan). The composition of the alloy, especially the segregation phase, was determined by energy spectrum analysis, and the microstructure was observed by JEM-2100 transmission electron microscope (JEOL Ltd., Tokyo, Japan) to determine the second phase structure. The working voltage of the transmission electron microscope is $200 \mathrm{kV}$. The phase composition of experimental alloy and simulated segregation alloy was determined by $\mathrm{X}$-ray diffractometer.

The polarization curves of the experimental alloy and the simulated alloy were tested by Gamry750 electrochemical workstation (Gamry Instruments, Warminster, PA, USA) by using three-electrode system. The opposite electrode was a square platinum sheet, and the reference electrode was a saturated calomel electrode (vs. SCE). The alloy to be tested was used as the working electrode, fixed with a special mold to ensure a working area of $1 \mathrm{~cm}^{2}$, and the depolarizer was a $3.5 \mathrm{wt} . \% \mathrm{NaCl}$ solution. The anode sample was soaked in the depolarizer to measure its open circuit potential. After the open circuit potential was stable, the polarization curve test was conducted. In order to test the polarization curve, the Luggin capillary should be as close to the surface of the working electrode as possible to reduce the influence on the solution resistance. The polarization scanning range of the polarization curve test was $\pm 0.2 \mathrm{~V}$ (vs. OCP), and the scanning rate was $1 \mathrm{mV} / \mathrm{s}$. Although a $1 \mathrm{mV} / \mathrm{s}$ is adopted in this stage of the experimentations, it is remarked that this selection has not provided substantial distortions in the polarization curves obtained. In this sense, it is worth noting that the potential scan rate has an important role in order to minimize the effects of distortion in Tafel slopes and corrosion current density analyses, as previously reported [31-34]. After the polarization curve test, the data were fitted by Echem Analyst software to obtain the corrosion potential and corrosion current data. The test sample and experimental conditions of alternating current $(\mathrm{AC})$ impedance were the same as those of the polarization curve. The alloy to be tested was soaked in the depolarizer to test its open circuit potential. After the open circuit potential is stable, the AC impedance test was carried out. The amplitude of the sinusoidal wave in the AC impedance test is $5 \mathrm{mV}$, with 10 points per decade and the frequency scanning range is $0.01 \mathrm{~Hz} 100 \mathrm{kHz}$. After the AC impedance test, Zsimpwin software (AMETEK, Oak Ridge, TN, USA) was used to perform equivalent circuit fitting.

The current efficiency was tested according to GB/T17848-1999. Using a special stainless-steel cylinder as a counter electrode, the total working area of the stainless steel cylinder was about $840 \mathrm{~cm}^{2}$ and the alloy to be tested was used as the working electrode. Furthermore, the working area was $14 \mathrm{~cm}^{2}$, the area ratio between anode and cathode was 60:1, and the saturated calomel electrode (vs. SCE) was used as the reference electrode. The counter electrode was fixed at a position of about $10 \mathrm{~cm}$ from the bottom surface of the electrolytic cell, and it was ensured that it does not expose the water surface. In addition, the working electrode was fixed to the center position of the stainless-steel cylinder. The Luggin capillary tube fixing the auxiliary electrode should be as close to the surface of the working electrode as possible to reduce the influence of solution resistance. The alloy sample to be tested was immersed in artificial seawater for $3 \mathrm{~h}$ and its open circuit potential was recorded. Using the Gamry750 electrochemical station (Gamry Instruments, Warminster, PA, USA) as a constant current source, the constant current of the alloy to be tested was $14 \mathrm{~mA}$, the constant current density was $1 \mathrm{~mA} / \mathrm{cm}^{2}$, the working potential of the alloy was recorded 2 3 times every $24 \mathrm{~h}$, and the total experimental time was $240 \mathrm{~h}$. Open circuit potential (OCP)refers to the electrode potential when the current density is zero, i.e., the potential difference between the working electrode and the reference electrode without load. Before the electrochemical test, the open circuit potential needs to be measured to observe the stability of the system. Working potential (CCP)is the electrode potential of sacrificial anode under external constant current, which reflects the actual situation of anode alloy in 
the working process. It is one of the important indexes of the current efficiency test. After the test, using xylene and other organic solvents to remove the package of the sample, and the alloy was immersed in $68 \% \mathrm{HNO}_{3}$ for $5 \sim 10 \mathrm{~min}$, and was then taken out and washed with water to remove the corrosion products on the alloy surface. The tested alloy sample was weighed to confirm the weight loss.

\section{Results and Discussion}

\subsection{Microstructure and Phase Analysis of Experimental Alloy}

The metallographic structure of the experimental alloy is shown in Figure 1. According to previous studies [35], the solubility of $\mathrm{Zn}$ in $\mathrm{Al}$ is about $2 \mathrm{wt} . \%$, and the solid solubility of Er in the aluminum matrix is very small, which is less than $0.04 \mathrm{wt} \%$ at room temperature. Additionally, it is only 0.4 0.6 wt.\% even at high temperature, the solid solubility of In in $\mathrm{Al}$ is only $0.014 \mathrm{wt} \%$, and the part exceeding the solid solubility will exist in the form of segregated phase in the alloy. During the casting of the alloy, the cast steel mold is preheated at $300{ }^{\circ} \mathrm{C}$ in advance, but there is still a large temperature difference between the cast steel mold and the high temperature liquid metal, which leads to the rapid cooling of the alloy, causing the as-cast alloy to form a typical dendritic structure and dendrite structure is larger. $\mathrm{Al}-5 \mathrm{Zn}-0.03 \mathrm{In}$ sample without $\mathrm{Er}$ is typical dendrite structure, and its dendrite structure is coarse. With the increase in Er content, the dendrite structure of $\mathrm{Al}-5 \mathrm{Zn}-0.03 \mathrm{In}-0.5 \mathrm{Er}$ alloy is refined, and the segregation of Al-5Zn-0.03In-0.5Er alloy decreases obviously. When the Er content reaches 1wt.\%, the alloy begins to transfer from the previous dendrite structure to the fine dendrite structure. When the addition of Er reaches $4 \mathrm{wt} . \%$, the grain structure of the alloy is further refined, and the precipitates at the grain boundary begin to increase.
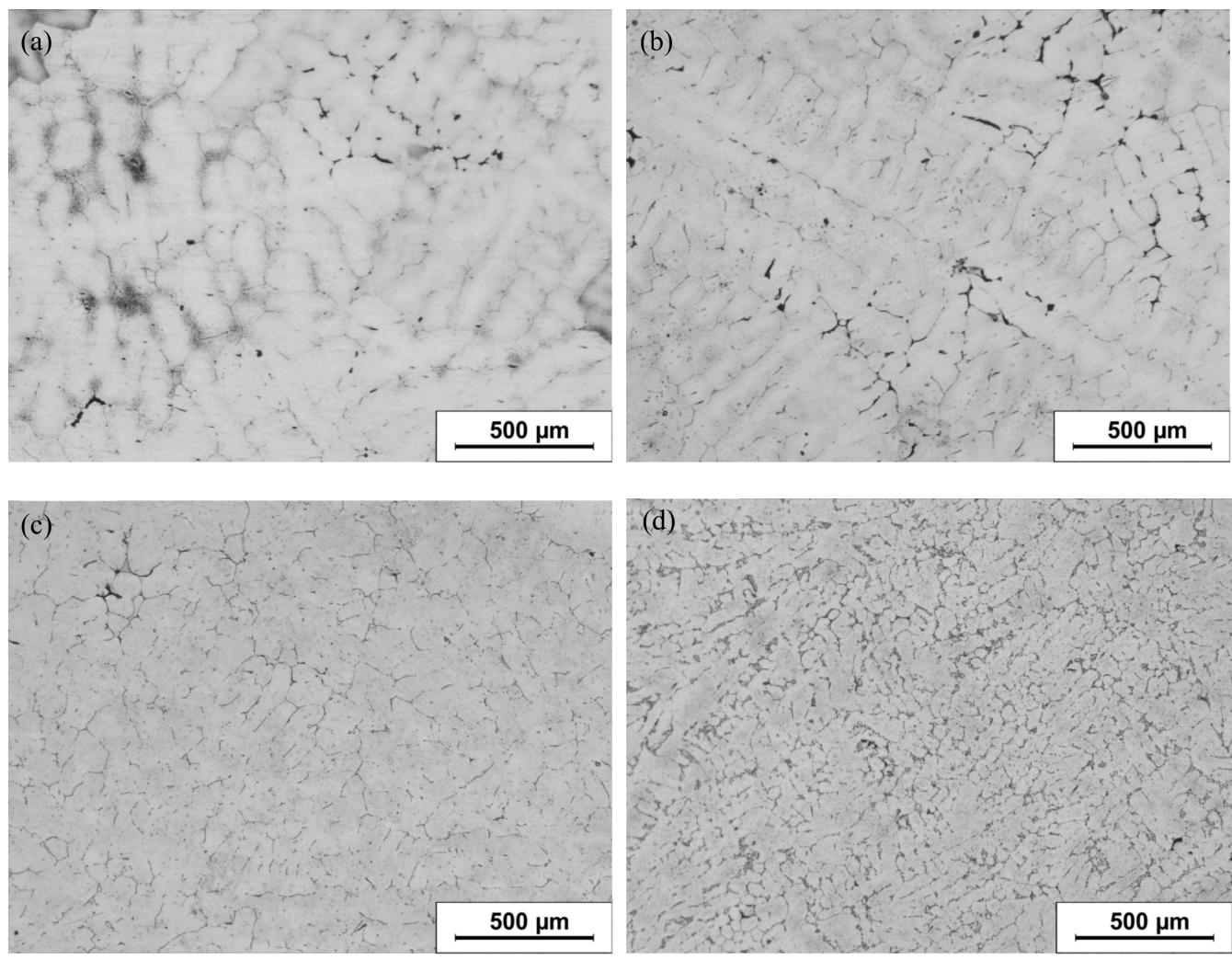

Figure 1. Optical microstructure of Al-5Zn-0.03In- $x$ Er alloys: (a) Al-5Zn-0.03In; (b) Al-5Zn-0.03In$0.5 \mathrm{Er} ;$ (c) Al-5Zn-0.03In-1Er; (d) Al-5Zn-0.03In-4Er.

Figure 2 shows the SEM picture of the Al-5Zn-0.03In- $x$ Er alloy at low magnification. The microstructure of the Al-5Zn-0.03In- $x$ Er alloy is mainly composed of $\alpha-\mathrm{Al}$ matrix and 
precipitated phase. In the picture, the dark part is solid solution, and the white part is grain boundary and precipitate.
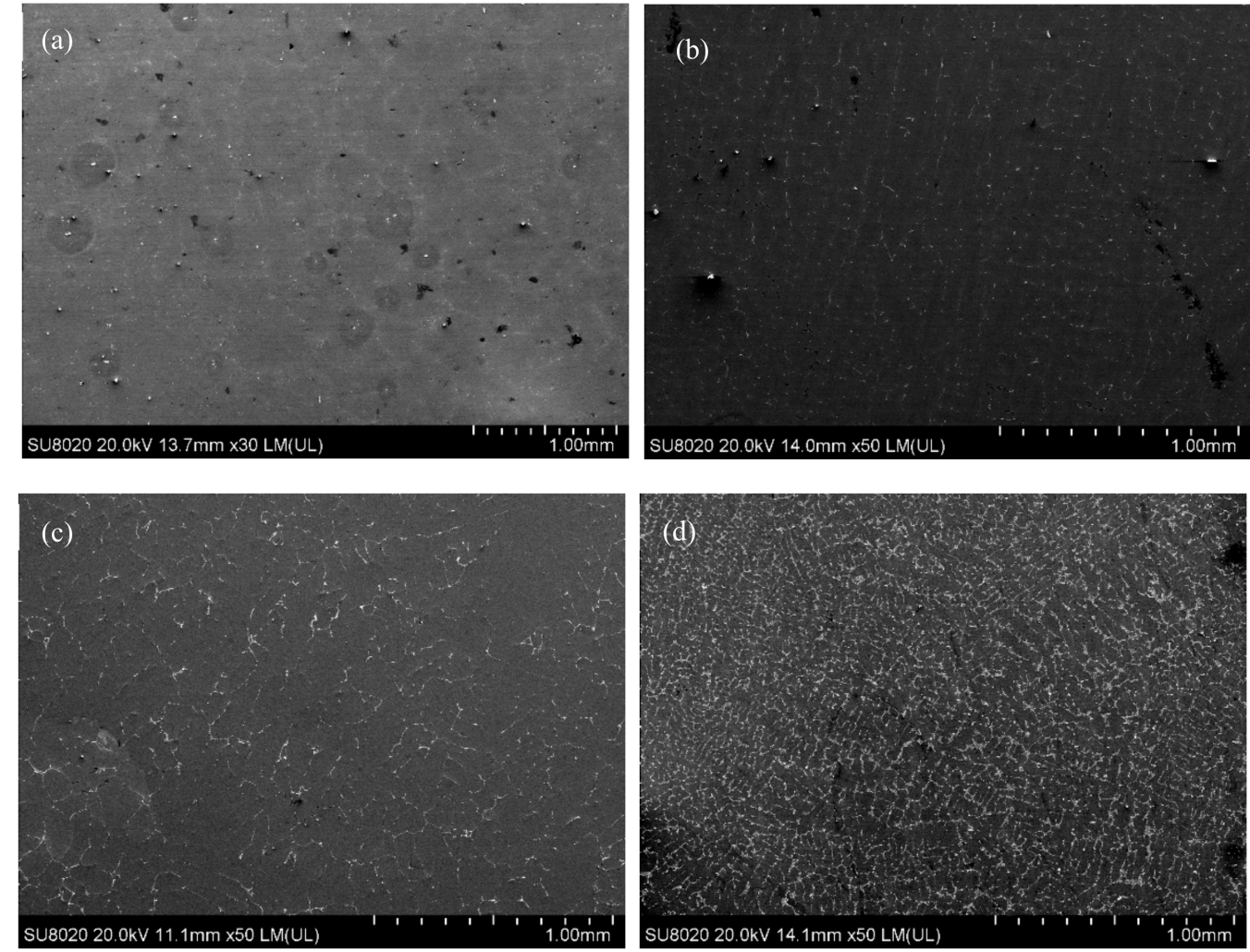

Figure 2. SEM images of Al-5Zn-0.03In- $x$ Er alloys: (a) Al-5Zn-0.03In; (b) Al-5Zn-0.03In-0.5Er; (c) Al-5Zn-0.03In-1Er; (d) Al-5Zn-0.03In-4Er.

It can be seen from Figure 2 that with the increase in the Er content in the alloy, the dendrite morphology changed from coarse to fine and equiaxed, the amount of interdendritic precipitates gradually increased, and the morphology changed from discontinuous to continuous network gradually. The results show that the grain boundary area of the Al-5Zn-0.03In- $x$ Er alloy increases with the increase in the amount of precipitates at the grain boundary, which indicates that the addition of Er has a significant refining effect on the grains of the Al-5Zn-0.03In- $x$ Er alloy and improves the microstructure of the alloy. It can be seen from the Al-Er binary phase diagram [36] that the equilibrium solid solubility of $\mathrm{Er}$ in $\mathrm{Al}$ is very low. Furthermore, at the aluminum-rich angle of the phase diagram, there is an $\mathrm{Al}-\mathrm{Al}_{3} \mathrm{Er}$ eutectic reaction, the eutectic reaction temperature is $655^{\circ} \mathrm{C}$, and the eutectic composition point is $6 \mathrm{wt}$ \% Er. During the solidification and crystallization of the alloy, Er is enriched in the front of the solid-liquid interface, which increases the content of Er near the interface. In the eutectic reaction process, Er enrichment intensifies at the interface front, which exceeds eutectic composition and directly forms $\mathrm{Al}_{3} \mathrm{Er}$ granular phase with high melting point from the melt. According to the related literature [37-39], on the one hand, the possible reason for grain refinement is that the primary $\mathrm{Al}_{3} \mathrm{Er}$ particles act as non-uniform nucleation core during solidification, which increases the nucleation rate; on the other hand, Er segregates at the grain boundary to form the $\mathrm{Al}_{3} \mathrm{Er}$ phase, which will also hinder grain growth.

Figure 3 shows the high magnification SEM images and EDS analysis results of the Al-5Zn-0.03In-1Er alloy. Area A is the matrix area of the test alloy, and area B is the white bright band at the grain boundary of the test alloy. EDS analysis shows that the matrix elements in the alloy are mainly composed of $\mathrm{Al}$ and $\mathrm{Zn}$, which is the $\alpha-\mathrm{Al}$ solid solution mentioned above, and most of the alloying elements in the white and bright band 
at the grain boundary are $\mathrm{Al}$ and $\mathrm{Er}$, which can be preliminarily identified as the $\mathrm{Al}_{3} \mathrm{Er}$ phase [40]. Er segregates at the grain boundary to form the $\mathrm{Al}_{3}$ Er phase, which will also hinder grain growth.
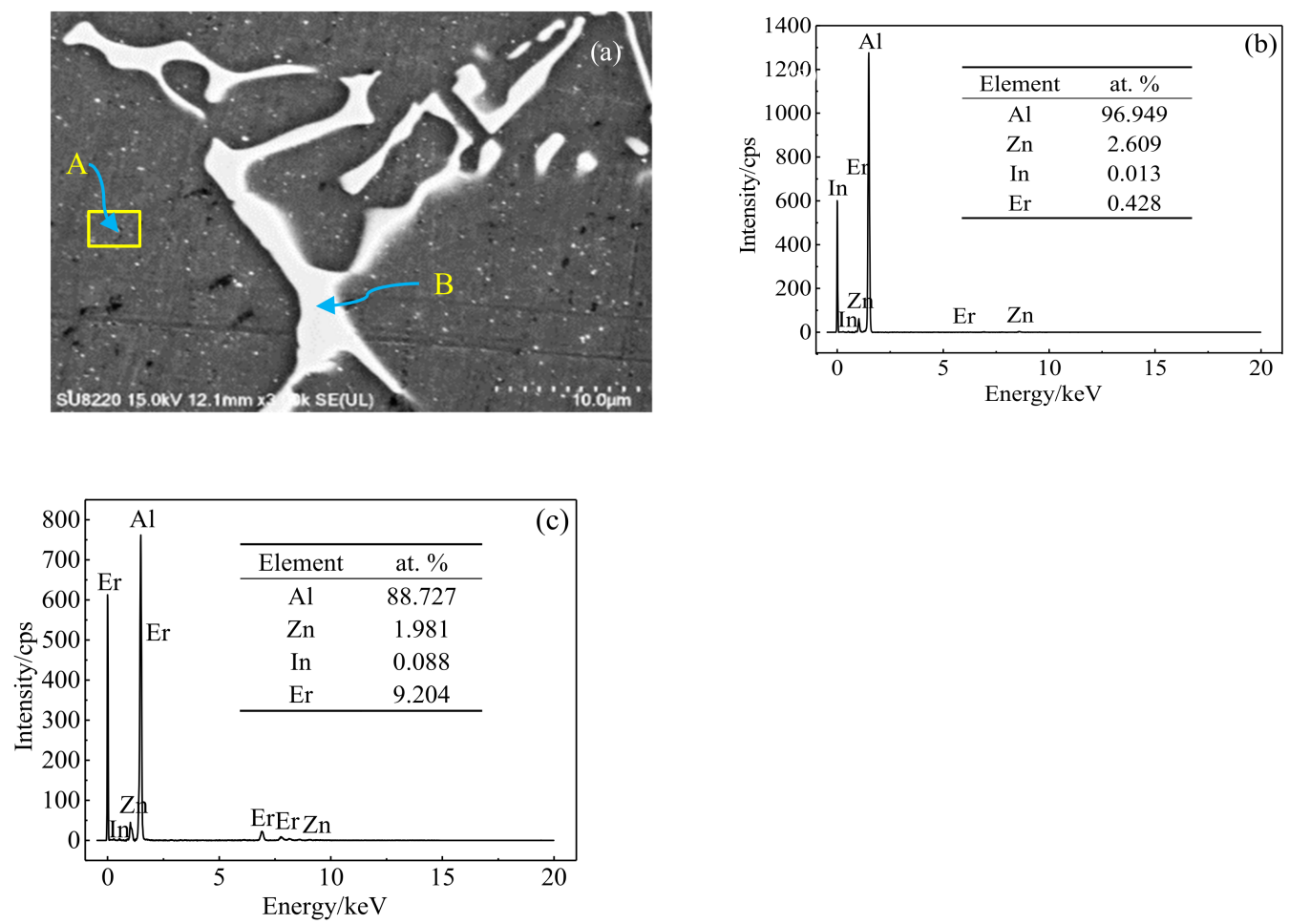

Figure 3. SEM image and EDS of Al-5Zn-0.03In-1Er alloy: (a) SEM photograph of Al-5Zn-0.03In$1 \mathrm{Er} ;$ (b) EDS of area A; (c) EDS of area B.

To further determine the composition of the precipitated phase, the test alloy was tested by XRD. The XRD results are shown in Figure 4. The composition of the Al-5Zn$0.03 \mathrm{In}$ alloy without Er is mainly the $\mathrm{Al}-\mathrm{Zn}$ solid solution. In addition to the $\mathrm{Al}-\mathrm{Zn}$ solid solution, there is also the $\mathrm{Al}_{3} \mathrm{Er}$ phase in the sample with an Er addition, and the diffraction peak intensity of $\mathrm{Al}_{3} \mathrm{Er}$ phase increases with the increase in Er content.

On this basis, the samples of the Al-5Zn-0.03In-1Er alloy were characterized by TEM. The TEM morphology of the samples is shown in Figure 5a. It can be seen that the second phase is enriched at the grain boundary.
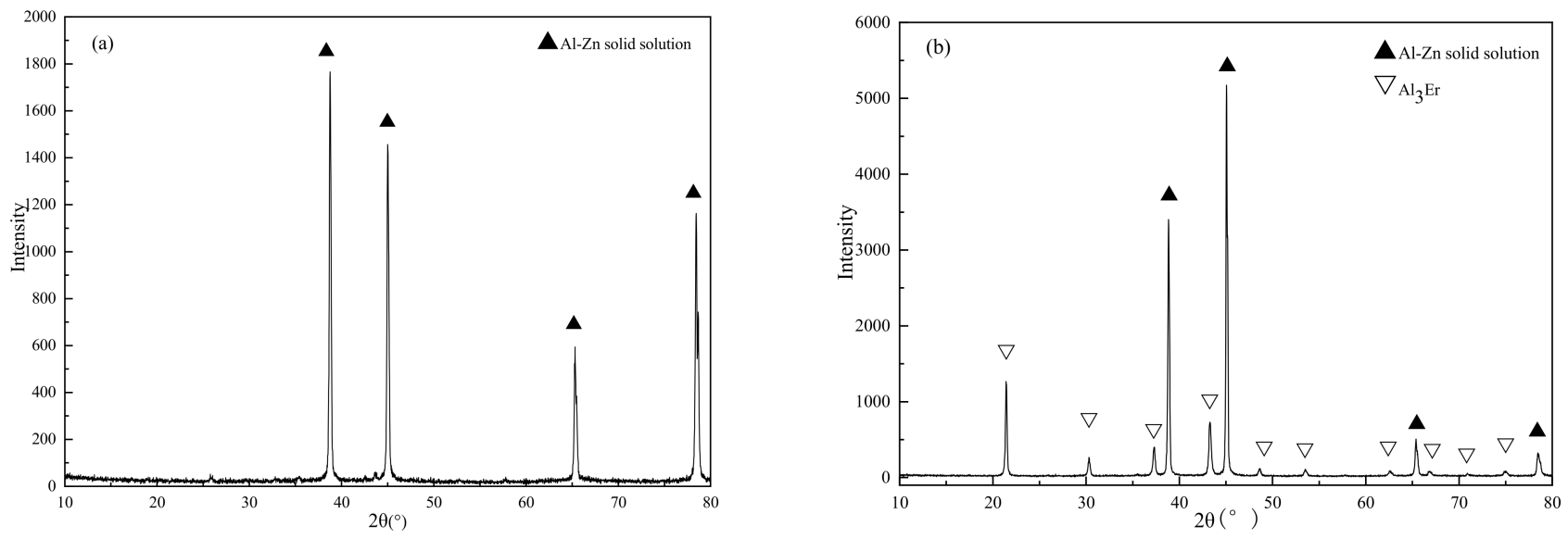

Figure 4. Cont. 


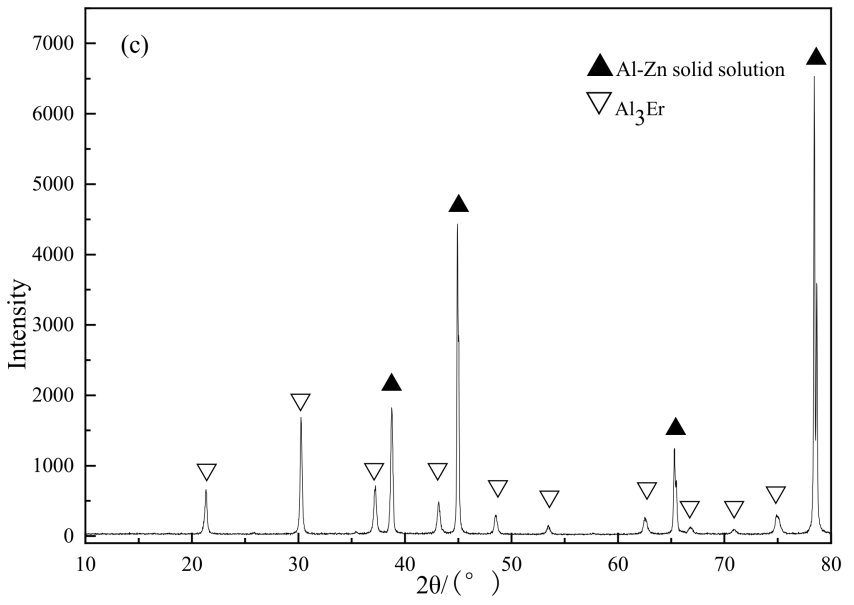

Figure 4. XRD analysis of Al-5Zn-0.03In- $x$ Er alloys: (a) Al-5Zn-0.03In; (b) Al-5Zn-0.03In-1Er; (c) Al-5Zn-0.03In-4Er. (Al 3 Er PDF\#17-0666, Al-Zn solid solution PDF\#52-0856).
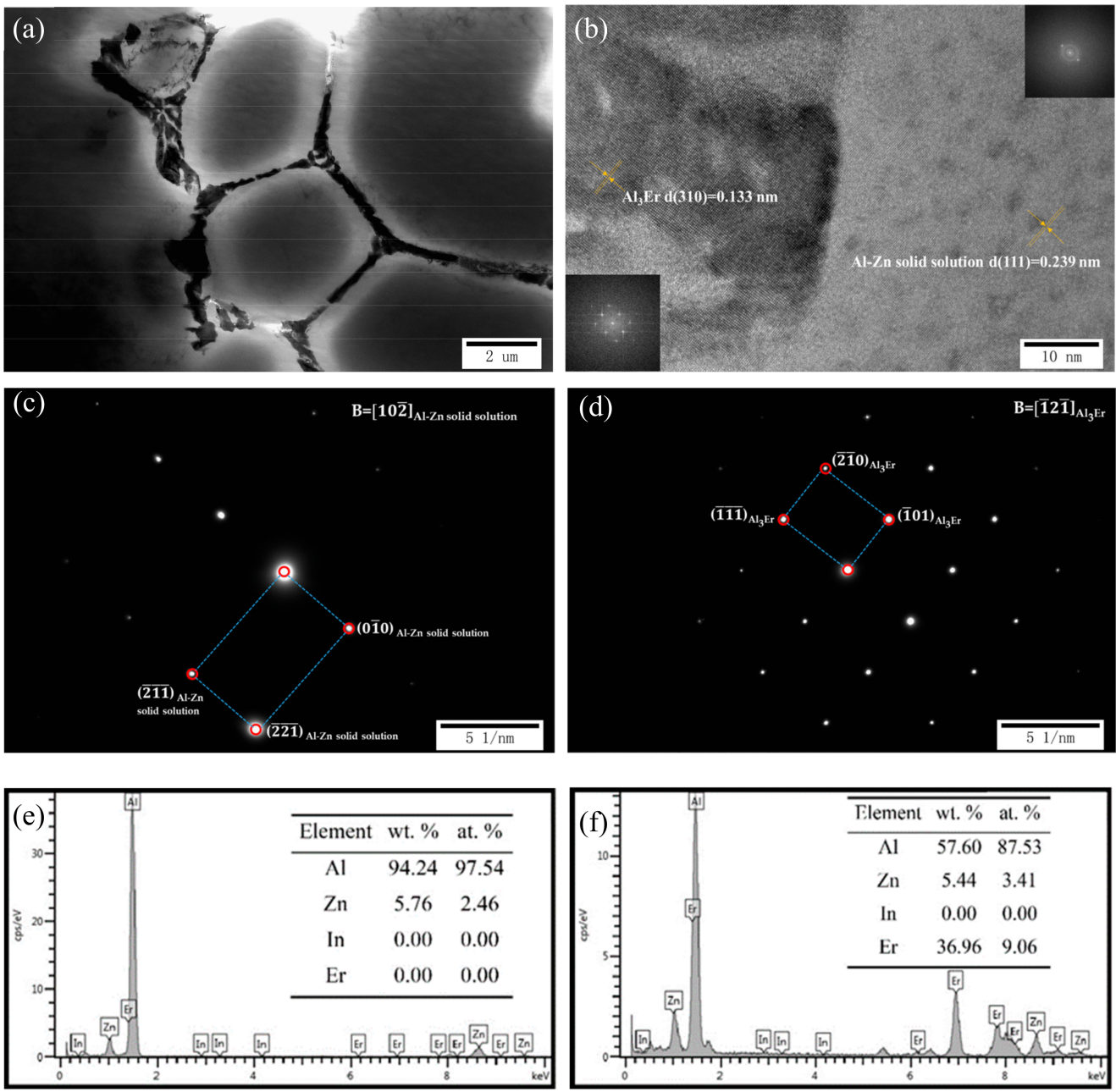

Figure 5. TEM images of the as-cast Al-5Zn-0.03In-1Er alloy: (a) TEM image, (b) HRTEM, (c) the SAEDP of the alloy matrix, (d) the SAEDP of the second phase, (e) the EDS of the alloy matrix, (f) the EDS of the second phase.

The high-resolution TEM characterization of both sides of the grain boundary is shown in Figure 5b, with the second phase on the left side and the matrix on the right side. The HRTEM is analyzed by Digital Micrograph (DM) software (AMETEK, Oak Ridge, TN, 
USA), and the results are shown in Figure 5b. On the lower left is the high resolution result of the second phase. The distance between the crystal planes is about $0.141 \mathrm{~nm}$, which is the result of the crystal plane of $\mathrm{Al}_{3} \mathrm{Er}$. The upper right is the result of high resolution of the matrix, and the distance between the crystal planes is about $0.138 \mathrm{~nm}$, which satisfies the distance between the crystal planes of the matrix. The selected area electron diffraction patterns (SAEDP) of the matrix and the second phase are shown in Figure $5 \mathrm{c}$,d. The calibration results meet the crystal face indices of the Al-Zn solid solution and $\mathrm{Al}_{3} \mathrm{Er}$. The EDS analysis of the sample shows that the EDS result of the TEM sample is close to that of the SEM sample. It can be considered that the precipitation phase in the experimental alloy containing $\mathrm{Er}$ is $\mathrm{Al}_{3} \mathrm{Er}$.

\subsection{Electrochemical Properties of Experimental Alloys}

\subsubsection{Polarization Curve Test of Al-5Zn-0.03In- $x$ Er Alloy}

Figure 6 shows the polarization curve of the Al-5Zn-0.03In- $x$ Er experimental alloy. With respect to the Al-5Zn-0.03In- $x$ Er alloy, the anodic polarization curve during electrode polarization reflects the rate of positive movement of alloy potential and its passivation trend when the current changes. Generally speaking, the lower the slope of the anode curve is, the lower the degree of polarization will be and the stronger the surface dissolution activity of the alloy will be. On the contrary, the higher the slope of the anode curve, the greater the degree of polarization will be, the stronger the tendency of passivation will be, and the lower the surface activity will be. The shape of the polarization curves of the Al$5 \mathrm{Zn}-0.03 \mathrm{In}-x$ Er experimental alloy is generally similar, the anodic polarization trend of the alloy is weak, and there is no obvious passivation phenomenon. The anodic current density of the alloy increases rapidly with the increase in anodic polarization potential, indicating that the four components of the Al-5Zn-0.03In- $x$ Er alloy can be actively dissolved in the overpotential range of the polarization curve test.

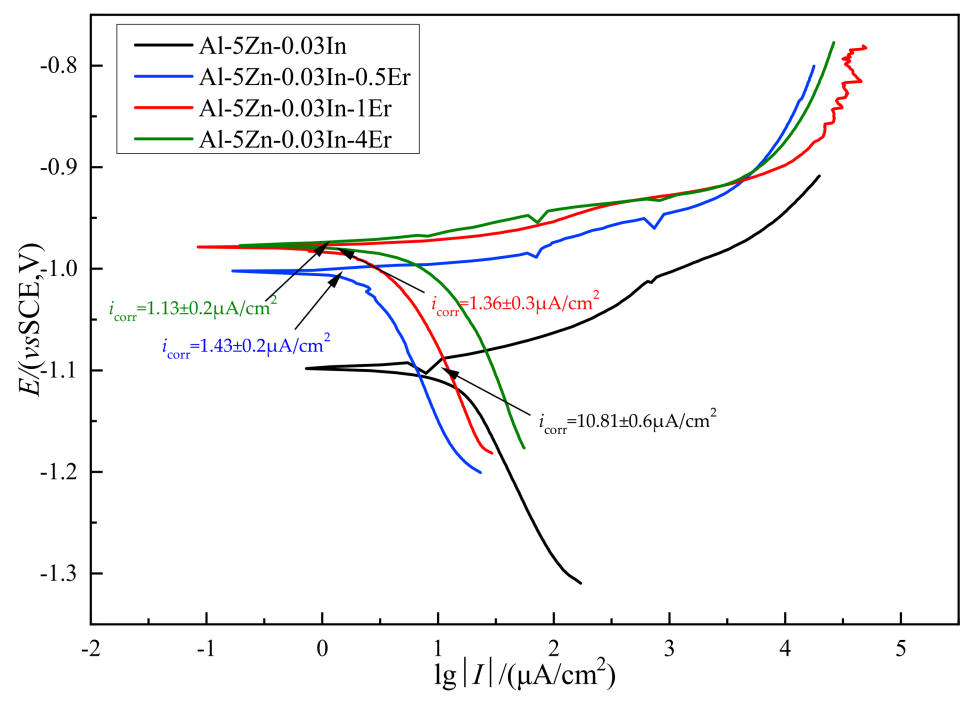

Figure 6. Polarization curves of Al-5Zn-0.03In- $x$ Er alloys.

The measured polarization curves were fitted by Echem Analyst software (Gamry Instruments, Warminster, PA, USA). The fitting values are shown in Table 2, with the increase in Er content in the Al-5Zn-0.03In- $x$ Er alloy, the self-corrosion potential $E_{\text {corr }}$ of the Al-5Zn-0.03In- $x$ Er alloy gradually moves positively, indicating that the increase in Er content decreases the activation properties of the Al-5Zn-0.03In- $x$ Er alloy. 
Table 2. Fitting values of polarization curve.

\begin{tabular}{ccc}
\hline Alloys & $\boldsymbol{E}_{\text {corr }}$ & $\boldsymbol{i}_{\text {corr }}$ \\
\hline Al-5Zn-0.03In & $-1098 \mathrm{mV}$ & $10.81 \pm 0.6 \mu \mathrm{A} / \mathrm{cm}^{2}$ \\
Al-5Zn-0.03In-0.5Er & $-1002 \mathrm{mV}$ & $1.43 \pm 0.2 \mu \mathrm{A} / \mathrm{cm}^{2}$ \\
Al-5Zn-0.03In-1Er & $-978.9 \mathrm{mV}$ & $1.36 \pm 0.3 \mu \mathrm{A} / \mathrm{cm}^{2}$ \\
Al-5Zn-0.03In-4Er & $-976.6 \mathrm{mV}$ & $1.13 \pm 0.2 \mu \mathrm{A} / \mathrm{cm}^{2}$ \\
\hline
\end{tabular}

When the Er content is in the range of $1 \mathrm{wt} . \%$, with the increase in Er content, the alloy's self-corrosion potential $E_{\text {corr }}$ moves positively, and the potential difference between Al-5Zn-0.03In and Al-5Zn-0.03In-1Er reaches $119.1 \mathrm{mV}$. When the Er content exceeds $1 \mathrm{wt} \%$, the positive move of the self-corrosion potential begins to slow down, and the potential difference between Al-5Zn-0.03In-1Er and Al-5Zn-0.03In-4Er is only $2.3 \mathrm{mV}$. Compared with the protection potential of steel $(-850 \mathrm{mV})$, the Al-5Zn-0.03In- $x$ Er alloy samples of all components have a lower corrosion potential than that of, which is still anode material compared to steel materials.

For most metal materials, the self-corrosion potential $\left(E_{\text {corr }}\right)$ represents the tendency of thermodynamics; a lower value of the self-corrosion potential means a greater corrosion tendency of the alloy in the electrochemical reaction. The self-corrosion current density $\left(i_{\text {corr }}\right)$ characterizes the kinetics of the alloy reaction, and its value is positively correlated with the corrosion rate of the material. The higher the self-corrosion current, the greater the corrosion tendency of the material will be. For specific alloy materials, the lower the $E_{\text {corr }}$ and the higher the $i_{\text {corr }}$ lead to a better anode performance and more obvious protection effect on the cathode material. However, if the self corrosion potential $\left(E_{\text {corr }}\right)$ is too low, the protected material will fall into "over protection state", and the cathode material will have hydrogen evolution reaction, which seriously reduces the protection effect.

Combined with microscopic observation, the addition of Er can obviously improve the microstructure of the Al-5Zn-0.03In- $x$ Er alloy, although it will cause a positive move of the $E_{\text {corr }}$ of the alloy's self-corrosion potential. Thus, its potential is still within the applicable range. The decrease in self-corrosion current density reduces the reactivity of the alloy to some extent. On the other hand, the corrosion resistance of the alloy is enhanced, the service life of the Al-5Zn-0.03In- $x$ Er alloy is prolonged, and the probability of current efficiency loss is reduced.

\subsubsection{AC Impedance Test of the Al-5Zn-0.03In- $x$ Er Alloy}

The electrochemical impedance spectroscopy reflects the reaction kinetics information of the alloy material in the electrochemical dissolution process, which is the corrosion reaction mechanism of the alloy. It can be seen from Figure 7 that the electrochemical impedance spectra of Al-5Zn-0.03In- $x$ Er alloys all show capacitive reactance arcs at high frequencies and inductive reactance arcs at low frequencies. According to the study of J.L.Ma et al. [41], it can be considered that, if the shape of the electrical impedance spectrum is similar, the dissolution process of the experimental alloy is similar to, or even the same as, kinetic mechanism. Furthermore, the size of high-frequency capacitive arc resistance of four Al-5Zn-0.03In- $x$ Er alloys increases with the addition of the Er element. In summary, it can be concluded that the addition of Er has no effect on the electrochemical corrosion mechanism of the $\mathrm{Al}-5 \mathrm{Zn}-0.03 \mathrm{In}-x \mathrm{Er}$ alloy. In other words, the four alloys have the same corrosion kinetic mechanism in $3.5 \% \mathrm{NaCl}$ solution, and the pitting corrosion is dominant. In the impedance spectrum, the low-frequency inductive reactance arc characterizes the pitting corrosion of the alloy. The pitting corrosion of the alloy is caused by the adsorption of corrosive anion $\mathrm{Cl}^{-}$on surface defects, such as dislocations and precipitation [42]. In this paper, it can be considered that the interaction between in $^{+}$and electrons in oxidation increases the defects in the oxide film, and these defects are mainly distributed at the thermodynamically unstable grain boundary and precipitated phase interface. The addition of Er will refine the dendrite structure, increase the interface area, and increase the number 
of precipitated phases, which further promotes the adsorption process of $\mathrm{Cl}^{-}$on the surface, resulting in typical pitting characteristics of the anode alloy, and a complete inductive reactance arc appears at low frequency in the electrochemical impedance spectrum.

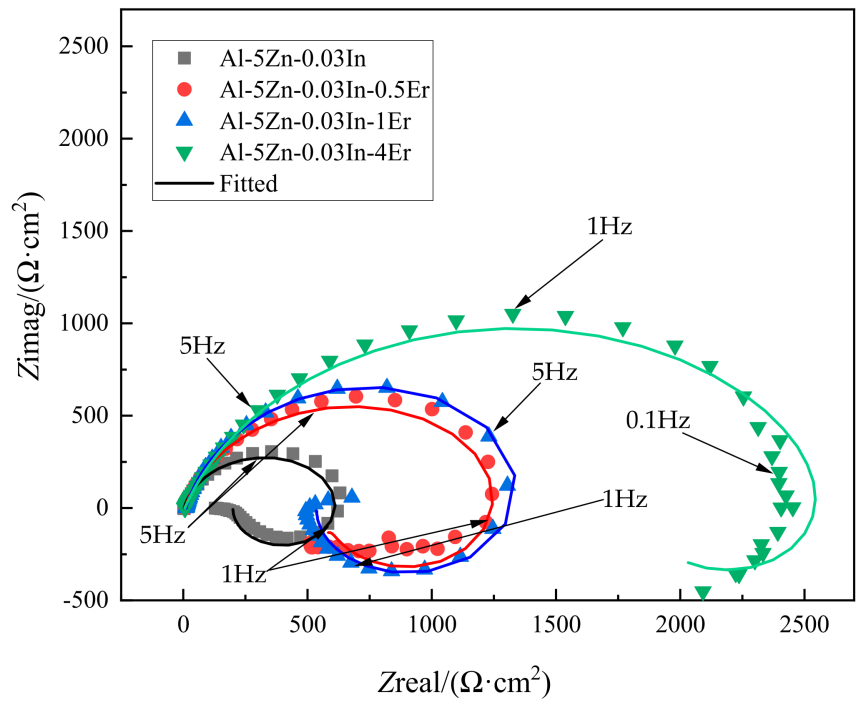

Figure 7. EIS of Al-5Zn-0.03In- $x$ Er alloys.

The addition of Er changes the impedance value of the Al-5Zn-0.03In- $x$ Er alloy. With the increase in Er content, the impedance value of the Al-5Zn-0.03In- $x$ Er alloy increased gradually. The original surface of the alloy without Er element is covered with a very thin passivation film, but due to the existence of $\mathrm{Zn}$, the oxidation film is relatively loose, and the presence of In increases the activity of the alloy. In addition, the charge transfer resistance become smaller, the relaxation process of double-layer capacitance is weaker, and the radius of capacitive arc curvature is smaller. With the increase in Er content, the segregation of $\mathrm{Zn}$ decreases, and Er itself is enriched in the interdendrite, which refines the alloy dendrite on the one hand. Additionally, the segregation phase increases and distributes evenly, and the alloy dissolves evenly. The addition of Er increases the transfer resistance of the alloy in the electrochemical process of the solution system, strengthens the bilayer capacitance relaxation process, and increases the radius of capacitive arc curvature. Compared with the alloy without Er, the dissolution rate of the alloy with Er is slowed down, and the corrosion resistance of the alloy is improved, which is consistent with the fitting results of the polarization curve.

After the AC impedance (EIS) test, the reliability of the measured data shall be verified before further data analysis. According to Kramers-Kronig (K-K) rules [43-45], the experimental impedance data were evaluated using Echem Analyst software. Figure 8 shows the $\mathrm{K}-\mathrm{K}$ conversion results of the real part (Zreal) and imaginary part (Zimag) of the test data. The K-K curve is highly consistent with the experimental results, as seen in Figure 8, which indicates that the electrochemical impedance data obtained in this study are reliable and can be used for further analysis.

The equivalent circuit fitting of the electrochemical impedance spectrum of Al-5Zn$0.03 \mathrm{In}-x$ Er is carried out using the ZSimpwin software (AMETEK, Oak Ridge, TN, USA), and the results are shown in Figure 9. When fitting the equivalent circuit of the electrochemical impedance spectrum of the alloy, the three electrical components commonly used are resistance $R$, capacitance $C$, and inductance $L$. Figure 9 is described by circuit symbol $R_{\text {sol }}$ $\left(Q R_{\mathrm{ct}}(L R)\right)$, where $R_{\mathrm{sol}}$ represents the resistance of the solution, $R_{\mathrm{ct}}$ represents the charge transfer resistance between the electric double layers on the alloy surface, $Q$ is $\mathrm{K}-\mathrm{K}$ curve constant phase element, and the range of parameter $n$ is $-1 \sim 1$. When $n=1, Q$ is equivalent to a capacitive element, when $n=0, Q$ is equivalent to a resistive element, and when $n=-1$, $Q$ is equivalent to an inductive element. $R$ represents the diffusion resistance of pitting 
corrosion, i.e., the resistance to the diffusion of intermediate products, and $L$ represents the adsorption behavior of intermediate corrosion products.
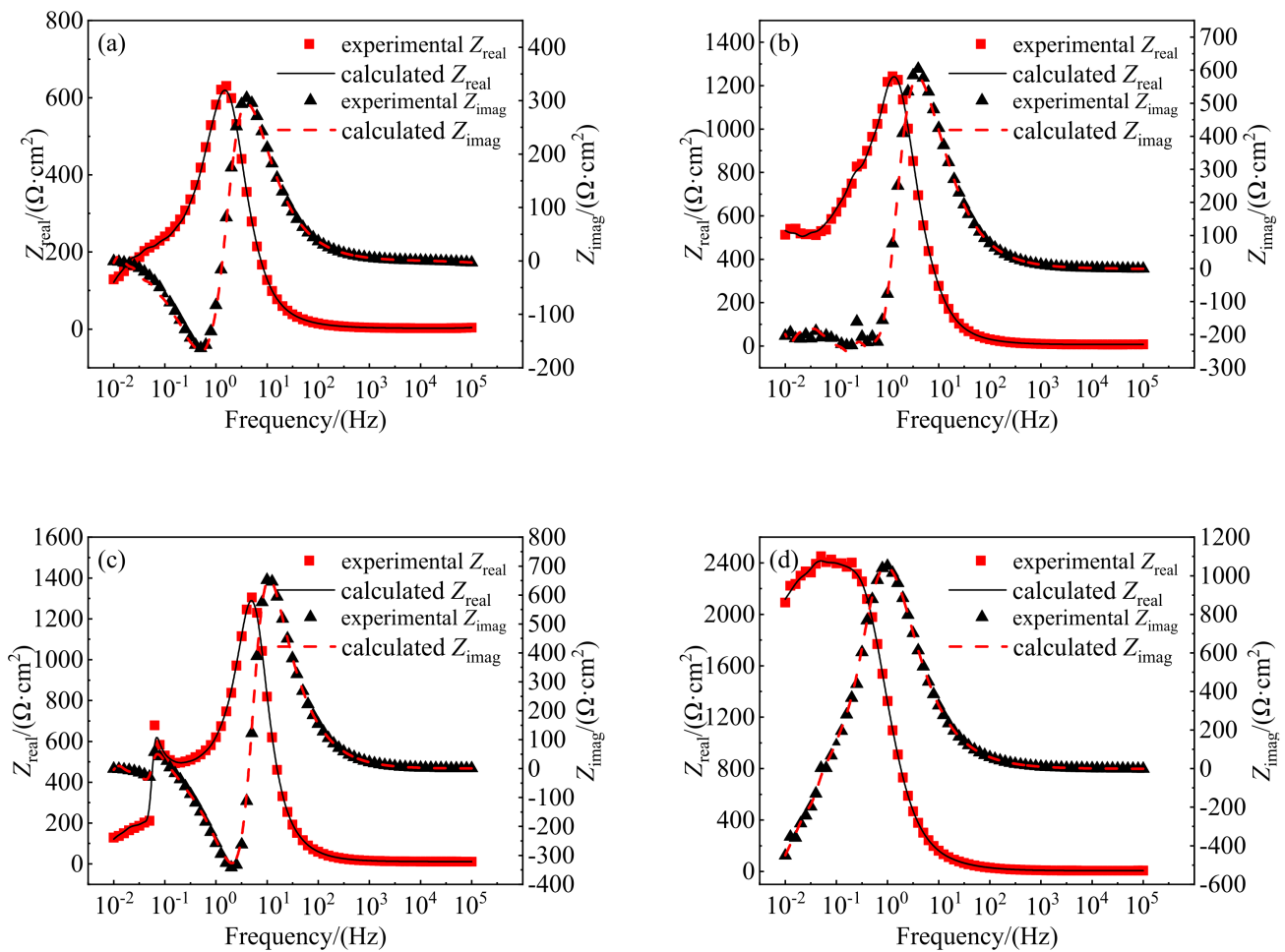

Figure 8. Typical Kramers-Kronig transforms of the real and imaginary components of the impedance of Al-5Zn-0.03In- $x$ Er alloys in 3.5 wt. $\% \mathrm{NaCl}$ solution: (a) Al-5Zn-0.03In; (b) Al-5Zn-0.03In-0.5Er; (c) Al-5Zn-0.03In-1Er; (d) Al-5Zn-0.03In-4Er.

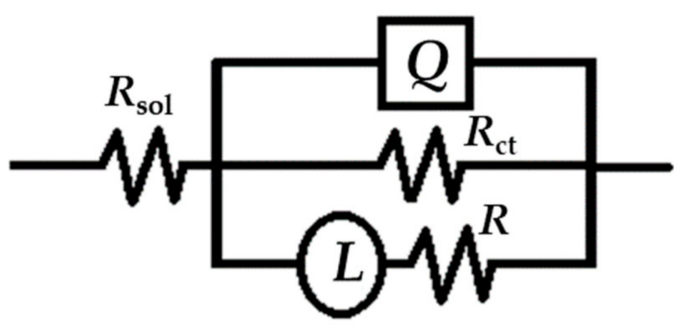

Figure 9. Equivalent circuit of Al-5Zn-0.03In- $x$ Er alloys.

Table 3 shows the values of the equivalent elements fitted by the equivalent circuit $R_{\text {sol }}\left(Q R_{\text {ct }}(L R)\right)$. It can be seen from Table 3 that all of the solution resistance $R_{\text {sol }}$ of the four Al-5Zn-0.03In $-x$ Er alloys is less than $10 \Omega \mathrm{cm}^{2}$. Thus, it can be considered that the solution resistance has a limited effect on the dissolution process of the alloy. Generally speaking, the charge transfer resistance $R_{\mathrm{ct}}$ of the alloy is inversely proportional to the corrosion current of the alloy; thus, the smaller the charge transfer resistance $R_{\mathrm{ct}}$, the faster the corrosion rate of the alloy.

It can be seen that the charge transfer resistance of the Al-5Zn-0.03In- $x$ Er alloy $R_{\mathrm{ct}}$ increases with the increase in Er content. The charge transfer resistance $R_{\mathrm{ct}}$ of the Al-5Zn0.03 In alloy without $\mathrm{Er}$ is the smallest, only $684.1 \Omega \cdot \mathrm{cm}^{2}$. The charge transfer resistance $\left(R_{\mathrm{ct}}\right)$ of Al-5Zn-0.03In-0.5Er, Al-5Zn-0.03In-1Er, and Al-5Zn-0.03In-4Er alloys with Er addition is $1356 \Omega \mathrm{cm}^{2}, 1801 \Omega \mathrm{cm}^{2}$, and $2528 \Omega \mathrm{cm}^{2}$, respectively. Moreover, the value raises with the increase in Er content, which was consistent with the fitting result of polarization curve that the corrosion resistance of the alloy is enhanced. In addition, the service life of 
the Al-5Zn-0.03In- $x$ Er alloy is prolonged, and the probability of current efficiency loss is reduced.

Table 3. Fitting values of EIS.

\begin{tabular}{|c|c|c|c|c|c|c|c|}
\hline Alloy & $R_{\mathrm{sol}}\left(\Omega \cdot \mathrm{cm}^{2}\right)$ & $R_{\mathrm{ct}}\left(\Omega \cdot \mathrm{cm}^{2}\right)$ & $Q\left(\Omega^{-1} \cdot \mathrm{cm}^{-2} \cdot \mathrm{s}^{-1}\right)$ & $n$ & $R\left(\Omega \cdot \mathrm{cm}^{2}\right)$ & $L\left(\mathrm{H} \cdot \mathrm{cm}^{2}\right)$ & $\chi^{2 *}$ \\
\hline $\mathrm{Al}-\mathrm{Zn}$-In & $3.35( \pm 0.16)$ & $684.1( \pm 114)$ & $9.147( \pm 1.1) \times 10^{-5}$ & 0.873 & $275.6( \pm 29)$ & 239.6 & $10.85 \times 10^{-3}$ \\
\hline $\mathrm{Al}-5 \mathrm{Zn}-0.03 \mathrm{In}-0.5 \mathrm{Er}$ & $7.07( \pm 0.15)$ & $1356( \pm 47.8)$ & $4.693( \pm 0.24) \times 10^{-5}$ & 0.861 & $910.1( \pm 46)$ & 976.8 & $6.25 \times 10^{-3}$ \\
\hline $\mathrm{Al}-5 \mathrm{Zn}-0.03 \mathrm{In}-1 \mathrm{Er}$ & $9.13( \pm 0.15)$ & $1801( \pm 79)$ & $2.227( \pm 0.11) \times 10^{-5}$ & 0.866 & $74.2( \pm 2)$ & 86.32 & $3.49 \times 10^{-3}$ \\
\hline Al-5Zn-0.03In-4Er & $6.35( \pm 0.16)$ & $2528( \pm 101.2)$ & $8.615( \pm 0.29) \times 10^{-5}$ & 0.809 & $4430( \pm 841)$ & 4.314 & $4.87 \times 10^{-3}$ \\
\hline
\end{tabular}

* Total Error $<15 \%$.

\subsubsection{Electrochemical Properties}

Table 4 shows the electrochemical properties of the alloys with various Er contents, compared with Al-5Zn-0.03In without Er. The open circuit potentials of the other three groups of samples with Er were all positively shifted to different degrees, and the open circuit potentials ranged from $-960 \mathrm{mV}$ to $\sim 1150 \mathrm{mV}$.

Table 4. Electrochemical properties of the Al-5Zn-0.03In- $x$ Er alloy.

\begin{tabular}{cccccc}
\hline Alloy & OCP/V & CCP/V & Q $/$ /A/(h·kg) & Q/A/(h/kg) & $\eta / \%$ \\
\hline Al-Zn-In & $-1.046 \sim-1.109$ & $-1.003 \sim-1.099$ & 2871.3 & 2340 & 81.4 \\
Al-5Zn-0.03In-0.5Er & $-0.963 \sim-1.027$ & $-0.939 \sim-1.043$ & 2858.8 & 2565 & 89.7 \\
Al-5Zn-0.03In-1Er & $-0.957 \sim-1.008$ & $-0.925 \sim-0.950$ & 2846.3 & 2414 & 84.8 \\
Al-5Zn-0.03In-4Er & $-0.996 \sim-1.120$ & $-0.941 \sim-0.967$ & 2771.3 & 1888 & 68.1 \\
\hline
\end{tabular}

The working potential of the Al-5Zn-0.03In- $x$ Er alloy after galvanostatic current has a relatively positive shift compared with its open circuit potential. Figure 10 shows the variation trend of the working potential of the Al-5Zn-0.03In- $x$ Er alloy with time. It can be seen that, compared with the initial experiment using an extended immersion time, the working potential of most $\mathrm{Al}-5 \mathrm{Zn}-0.03 \mathrm{In}-x \mathrm{Er}$ alloy has a positive trend. Since the Al-5Zn-0.03In- $x$ Er alloy was exposed to static artificial seawater during the whole experiment, in the corrosion process of the alloy, the corrosion products cannot quickly diffuse into the experimental solution, and the concentration of corrosion products in the solution also increases with the extension of time. Therefore, the adsorption phenomenon of corrosion products will appear on the surface of the Al-5Zn-0.03In- $x$ Er alloy, which is the main reason for the positive shift of the working potential of the alloy. The working potential of Al-5Zn-0.03In-1Er and Al-5Zn-0.03In-4Er alloys has a significantly positive shift after electrification, but the fluctuation of the working potential was small. The working potential of $\mathrm{Al}-5 \mathrm{Zn}-0.03 \mathrm{In}$ and $\mathrm{Al}-5 \mathrm{Zn}-0.03 \mathrm{In}-0.5 \mathrm{Er}$ alloys was negative and kept below $-1 \mathrm{~V}$ for most of the time. However, its working potential fluctuates more seriously at the beginning of electrification and gradually stabilizes after a period of electrification.

The theoretical capacitance of Al, Zn, In, and Er are $2980 \mathrm{~A} /(\mathrm{h} \cdot \mathrm{kg}), 820 \mathrm{~A} /(\mathrm{h} \cdot \mathrm{kg}), 700$ $\mathrm{A} /(\mathrm{h} \cdot \mathrm{kg})$, and $481 \mathrm{~A} /(\mathrm{h} \cdot \mathrm{kg})$. The low theoretical capacitance of Er may be the reason of theoretical capacitance decrease in the experimental alloy with Er contents.

Generally, the current efficiency of the anode alloy is calculated as follows:

$$
Q_{0}=A \cdot X+B \cdot Y+C \cdot Z+\cdots
$$

where $Q_{0}$ is the theoretical capacitance of anode, $A \cdot \mathrm{h} / \mathrm{kg} ; A, B, C$ represent the percentage of alloying elements $\% ; X, Y, Z$ represent the theoretical capacitance of alloying elements, $A \cdot \mathrm{h} / \mathrm{kg}$.

Actual capacity:

$$
Q=1000 \times C /\left(m_{1}-m_{2}\right)
$$


where $Q$ is the actual capacity of anode, $A \cdot \mathrm{h} / \mathrm{kg} ; C$ is total amount of electricity passed during the test cycle, $\mathrm{A} \cdot \mathrm{h} ; m_{1}$ represents the quality of a sample before testing, $\mathrm{g} ; m_{2}$ represents the quality of a sample before testing, $g$.

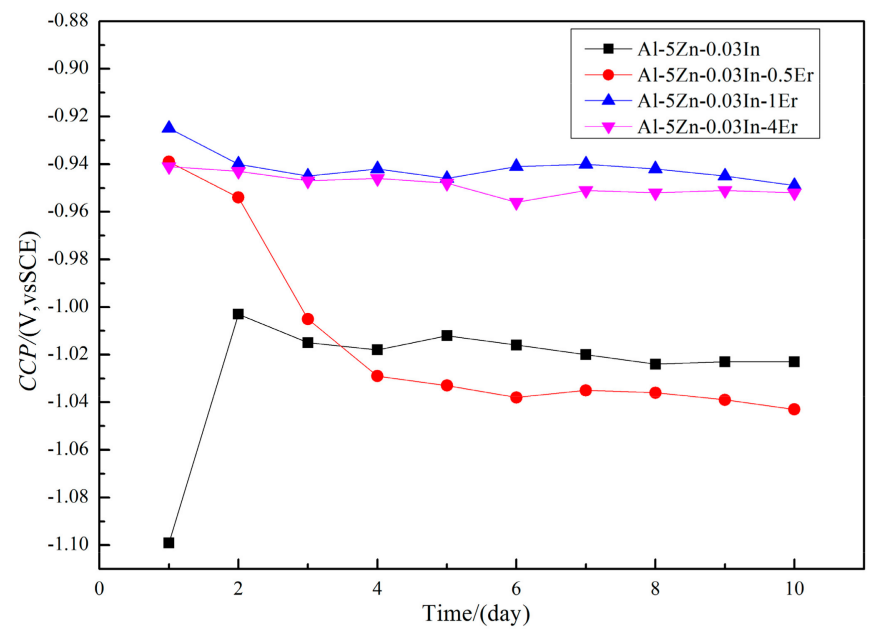

Figure 10. CCP of Al-5Zn-0.03In- $x$ Er alloys.

Calculation of current efficiency:

$$
\eta(\%)=\left(Q / Q_{0}\right) \times 100
$$

where $\eta$ is the current efficiency of anode alloy, $\%$.

According to the current efficiency formula, the current efficiency is the quotient of the actual capacitance and the theoretical capacitance; thus, the lower the theoretical capacitance is, the higher the current efficiency is. However, due to the actual addition of Er changes in the microstructure morphology of the alloy, its actual capacity will also change, so the actual current efficiency of the alloy must be determined by experiment.

Figure 11 shows the histogram of current efficiency of the Al-5Zn-0.03In- $x$ Er alloy. The current efficiency of the Al-5Zn-0.03In-0.5Er alloy is the highest, and that of the Al-5Zn-0.03In-4Er alloy with the most Er addition is the lowest (only 68.1\%). It can be seen that the addition of a small amount of Er can increase the current efficiency of the Al-5Zn-0.03In- $x$ Er alloy. When the addition amount of Er reaches 1\%, the increase in current efficiency decreases. However, when the addition amount of Er is too high, the current efficiency of Al-5Zn-0.03In- $x$ Er alloy decreases significantly. A small amount of Er can refine the grain size of $\mathrm{Al}-5 \mathrm{Zn}-0.03 \mathrm{In}-x$ Er alloy, improve its dissolution uniformity, and enhance the current efficiency of the alloy. At this time, grain refinement is the main factor affecting the current efficiency of the Al-5Zn-0.03In- $x$ Er alloy. When excessive Er exists as the form of intergranular segregation in the Al-5Zn-0.03In- $x$ Er alloy, the self-corrosion and grain shedding of Al-5Zn-0.03In- $x$ Er alloy increase, and the preferential dissolution of Er-rich precipitates leads to the loss of current efficiency.

Through the above comprehensive analysis, when the Er content is about 1\%, the microstructure of the alloy has been remarkably refined, the surface dissolution is improved, and the current efficiency is increased. Although the current efficiency of Al-5Zn-0.03In$1 \mathrm{Er}$ is slightly lower than that of $\mathrm{Al}-5 \mathrm{Zn}-0.03 \mathrm{In}-0.5 \mathrm{Er}$, the higher corrosion resistance prolongs the service life of the alloy, which saves the cost and avoids potential safety hazards caused by alloy failure in use. 


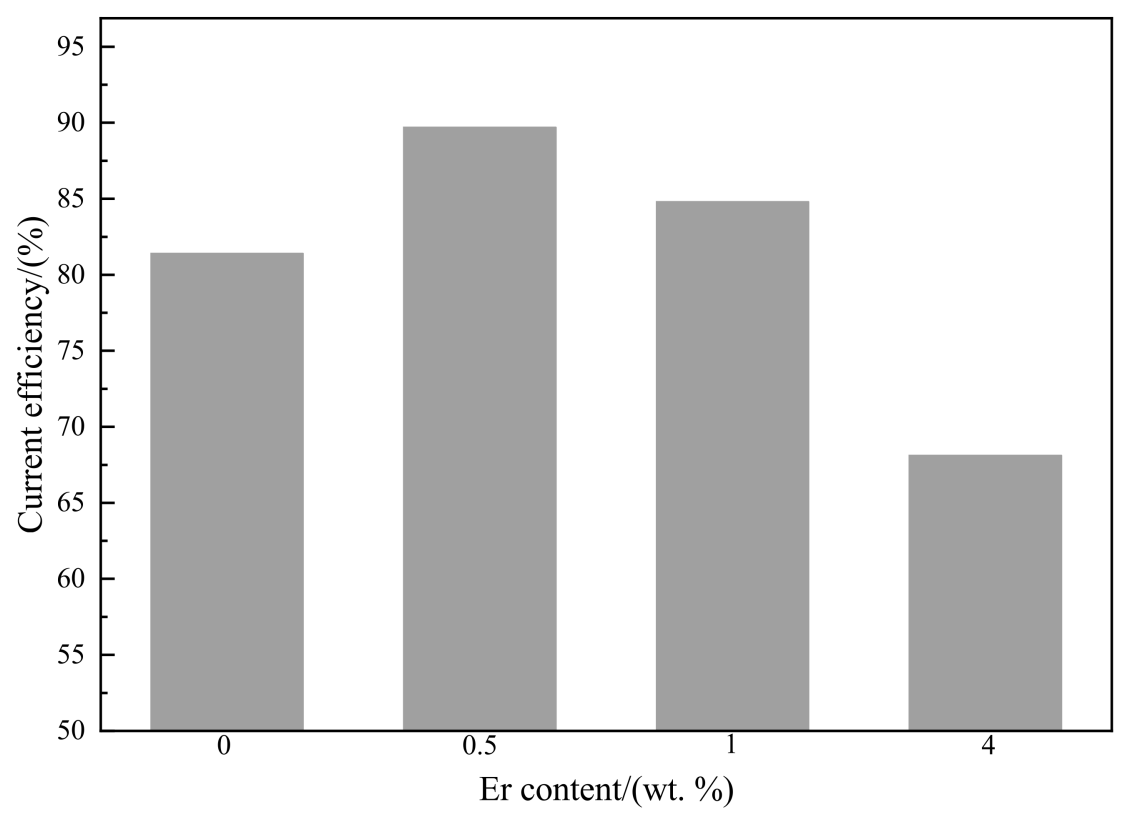

Figure 11. Current efficiency of Al-5Zn-0.03In- $x$ Er alloys.

\subsubsection{The Corrosion Morphology of Al-5Zn-0.03In- $x$ Er Alloy}

Figure 12 shows the SEM images and EDS analysis of the corrosion morphology in partial Al-5Zn-0.03In- $x$ Er alloys. All of the alloys have typical pitting corrosion. A large number of pitting pits are distributed on the surface of the alloy, and white corrosion products are attached in the middle of the pits. In addition, the white massive phase at the pitting of Al-5zn-0.03In is mainly composed of $\mathrm{Al}, \mathrm{Zn}$, and $\mathrm{O}$ and a small amount of In by EDS analysis. It was speculated, mainly by the oxidized product $\mathrm{ZnAl}_{2} \mathrm{O}_{4}$ and some $\mathrm{Al}_{2} \mathrm{O}_{3}$, due to the phenomenon of "dissolution redeposition", that a small amount of In is deposited on the surface. In addition to the above elements, there are Er elements in Al-5Zn-0.03In-1Er and Al-5Zn-0.03In-4Er added with Er, which should be the Er-rich phase with incomplete exfoliation.

It can be seen that the corrosion behavior of $\mathrm{Al}-5 \mathrm{Zn}-0.03 \mathrm{In}-x \mathrm{Er}$ alloy is mainly controlled by the "dissolution redeposition" of $\mathrm{Zn}$ and in elements and the preferential dissolution and exfoliation of $\mathrm{Al}_{3} \mathrm{Er}$ segregation phase. At the initial stage of dissolution, Al $-5 \mathrm{Zn}-0.03 \mathrm{In}-x$ Er alloy is mainly caused by pitting corrosion. The activation process of the alloy is related to the "dissolution redeposition" of $\mathrm{Zn}$ and in elements. The alloy elements enter the solution in the form of ions. When the matrix and oxide film form a corrosion galvanic couple, the alloy cations entering the solution are adsorbed on the surface of the alloy. By consuming the electrons generated by the dissolution of the alloy, the cation is reduced to atomic state and deposited on the surface of the alloy, and this process is continuously recycled to continuously activate the alloy, so we can detect the presence of a small amount of In on the surface of the alloy. When the amount of Er is small, it mainly affects the microstructure of the alloy, and the microstructure of the alloy is refined. Therefore, the addition of a small amount of Er can increase the current efficiency of the alloy. However, when the addition amount of Er is large, because Er mainly exists as the form of $\mathrm{Al}_{3} \mathrm{Er}$ and other segregation phases in the Al-5Zn-0.03In $-x \mathrm{Er}$ alloy, the number of segregation phase in the alloy increases sharply, and its distribution pattern is irregular. The segregation phase, the matrix, and other segregation phases form corrosion galvanic couples, and the preferential dissolution and shedding of the segregation phase may occur during the dissolution process, leading to the loss of current efficiency. 

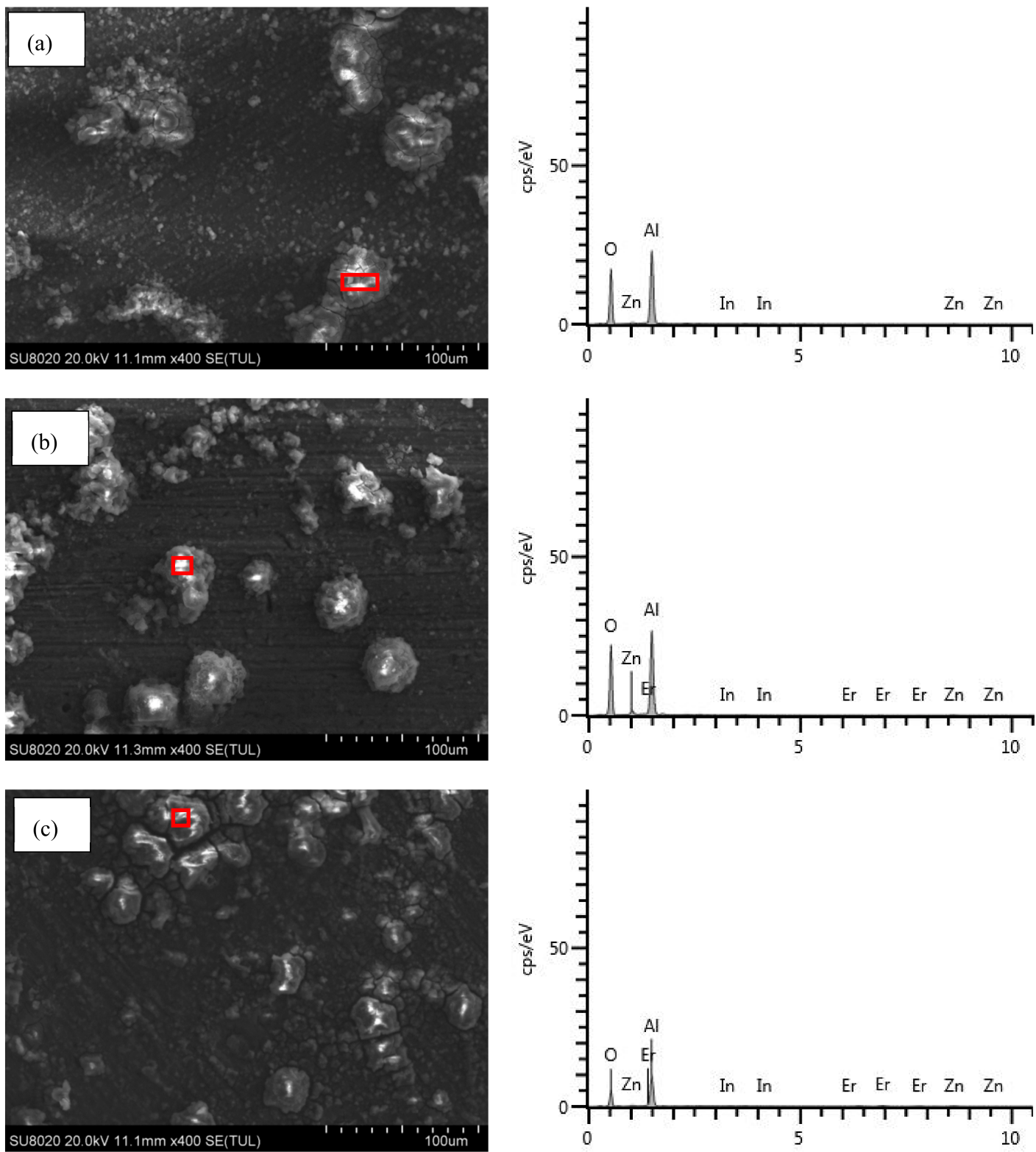

Figure 12. Corrosion morphologies and EDS analysis of Al-5Zn-0.03In- $x$ Er alloys: (a) Al-5Zn-0.03In; (b) Al-5Zn-0.03In-1Er; (c) Al-5Zn-0.03In-4Er.

\subsection{Microstructure and Phase Detection of Simulated Alloy}

According to the microstructure and phase analysis above, the Er element in Al-Zn-In$x$ Er alloy mainly exists in the form of interdendritic segregation phase, and the main form is $\mathrm{Al}_{3}$ Er. In order to study the segregation phase in the alloy, the simulated-segregation-phase alloy was configured and prepared according to $\mathrm{Al}_{3} \mathrm{Er}$. To ensure the uniform composition of the simulated alloy in the high-speed cooling in the electric arc furnace, long-term annealing treatment was carried out. The composition of the simulated alloy was detected by XRD. Figure 13 shows the XRD pattern of the $\mathrm{Al}_{3} \mathrm{Er}$-simulated alloy. After calibration, the main diffraction peaks in Figure 13 are consistent with those of standard $\mathrm{Al}_{3} \mathrm{Er}$ and a small amount of $\mathrm{Al}_{2} \mathrm{Er}$ compounds, which has little effect on the subsequent analysis. It can be concluded that $\mathrm{Al}_{3} \mathrm{Er}$ is the main component of the segregation simulated alloy obtained by melting. 


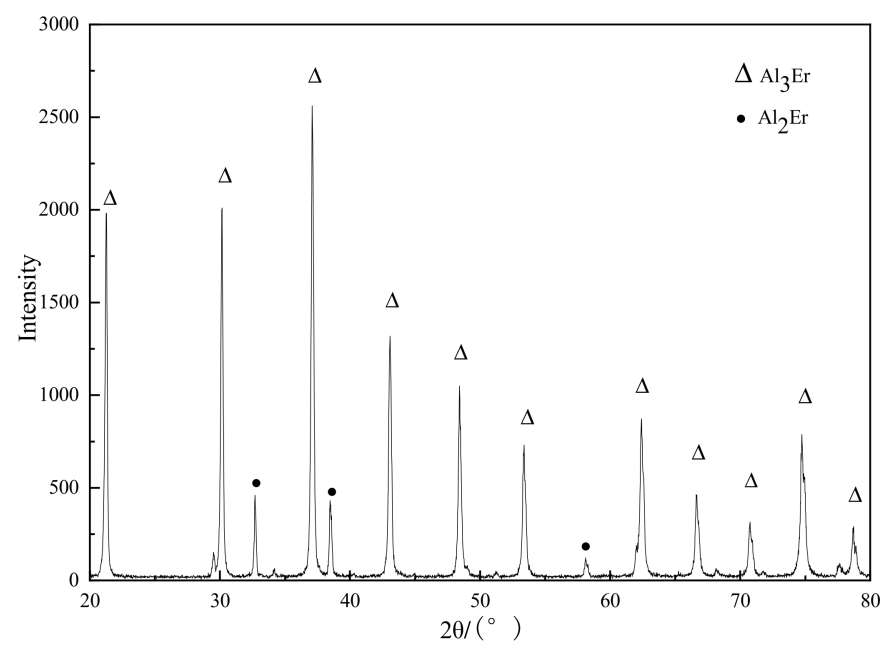

Figure 13. XRD pattern of $\mathrm{Al}_{3} \mathrm{Er}$ alloy ( $\left.\mathrm{Al}_{3} \mathrm{Er} \mathrm{PDF} 17-0666, \mathrm{Al}_{2} \mathrm{Er} \mathrm{PDF} \# 17-0667\right)$.

\subsection{Electrochemical Properties of Simulated Alloy}

\subsubsection{Polarization Properties of Simulated Alloy}

Figure 14 is the polarization curve diagram of the $\mathrm{Al}_{3}$ Er-simulated alloy and $\mathrm{Al}-\mathrm{Zn}-\mathrm{In}$ alloy. The anodic polarization trend of the Al-Zn-In alloy is small, the curve is relatively flat, and there is no obvious passivation phenomenon. The anode current density of the alloy increases rapidly with the increase in the anode polarization potential. It can be considered that, in the overpotential range tested by the polarization curve, the Al- $\mathrm{Zn}-\mathrm{In}$ alloy has no obvious passivation interval; this is because the $\mathrm{Zn}$ and In elements in the $\mathrm{Al}-\mathrm{Zn}$-In alloy have the effect of activation, and the process of "dissolution-redeposition" takes place on the alloy surface to promote the continuous activation of aluminum alloy so that a complete passive film will not be formed on its surface again. The "dissolutionredeposition" theory was proposed by Reboul et al. [46] in 1984, which can explain the activation of $\mathrm{In}, \mathrm{Hg}, \mathrm{Sn}$, and other elements in aluminum-based anodes better, so it has been widely recognized. The "dissolution-redeposition" theory divides the activation process of aluminum alloy anodes into the following steps.

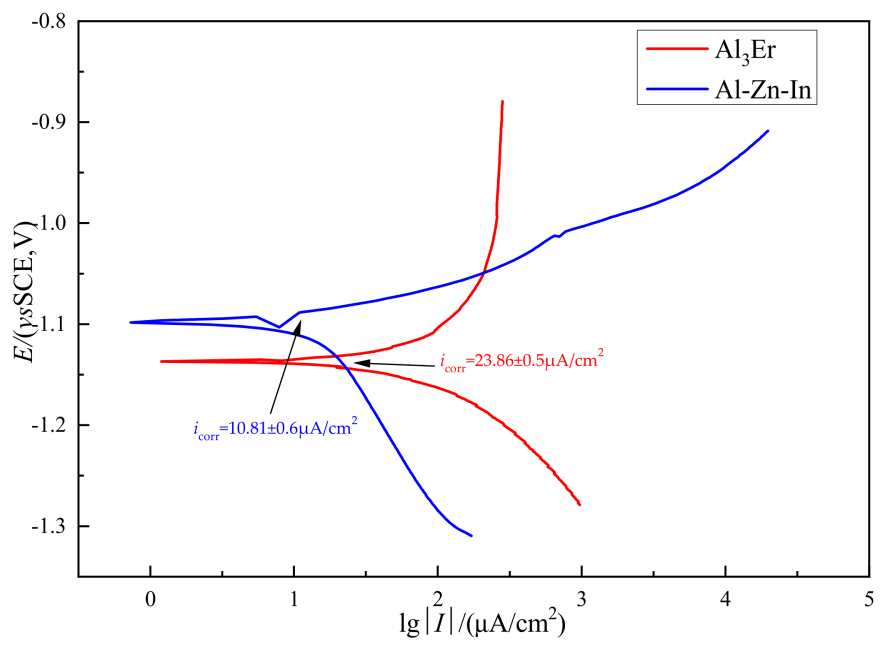

Figure 14. Polarization curves of $\mathrm{Al}-\mathrm{Zn}-\mathrm{In}$ and $\mathrm{Al}_{3} \mathrm{Er}$ alloys.

(1) The alloy elements are oxidized into cations and enter the electrolyte:

$$
\mathrm{Al}(M) \rightarrow x \mathrm{Al}^{3+}+M^{\mathrm{n}+}+y \mathrm{e}^{-}
$$


(2) Cations are reduced by $\mathrm{Al}$ and deposited on the surface of the alloy

$$
\mathrm{Al}+\mathrm{M}^{\mathrm{n}+} \rightarrow \mathrm{Al}^{3+}+\mathrm{M}
$$

(3) The stability and integrity of the oxide film are destroyed because of the partial separation of the oxide film.

(4) The above process can then be repeated, and the alloy is continuously activated.

When the polarization potential of the $\mathrm{Al}_{3} \mathrm{Er}$-simulated alloy reached about $-1.1 \mathrm{~V}$, the anode current density of the alloy almost stopped increasing, and the alloy exhibited passivation. The results show that Er element cannot play an active role in pure aluminum, and a complete passive film is formed on the surface of the alloy.

Table 5 shows the polarization curve fitting value of the $\mathrm{Al}_{3}$ Er-simulated alloy and the Al-Zn-In alloy. The self-corrosion potential is $-1098 \mathrm{mV}$ for the Al-Zn-In alloy and $-1136 \mathrm{mV}$ for the $\mathrm{Al}_{3} \mathrm{Er}$ alloy. Compared with the matrix alloy, the self-corrosion potential of the segregation alloy is $-38 \mathrm{mV}$. The self-corrosion current density of the Al- $\mathrm{Zn}-\mathrm{In}$ alloy and $\mathrm{Al}_{3}$ Er alloy are $10.81 \mu \mathrm{A} / \mathrm{cm}^{2}$ and $23.86 \mu \mathrm{A} / \mathrm{cm}^{2}$, respectively. The self-corrosion current density of the simulated-segregated-phase alloy is $13.05 \mu \mathrm{A} / \mathrm{cm}^{2}$ higher than that of the matrix alloy. Compared with the $\mathrm{Al}-\mathrm{Zn}$-In alloy, the $\mathrm{Al}_{3} \mathrm{Er}$ alloy is an anode-phase alloy. The anodic segregation phase is distributed in the oxide film on the surface of the $\mathrm{Al}-\mathrm{Zn}$-In alloy, which increases the defects of the oxide film and accelerates the shedding of the oxide film at the initial stage of dissolution. On the other hand, in the micro-corrosion cell formed by the $\mathrm{Al}_{3} \mathrm{Er}$ segregation phase and the $\mathrm{Al}-\mathrm{Zn}$-In alloy, the segregation phase dissolves preferentially because of its anodic polarity, which leads to the local damage of the $\mathrm{Al}_{2} \mathrm{O}_{3}$ oxide film. However, when the $\mathrm{Al}_{3} \mathrm{Er}$ segregation phase was soaked in depolarizer for a certain time, the simulated-segregation-phase alloy was passivated, the complete passivation film appeared again on the alloy surface, the "dissolution-redeposition" process of elements (such as In and Zn) was inhibited, the vacancy diffusion process in the oxide film was promoted, and the dissolution activity of Al-5Zn-0.03In- $x$ Er alloy decreased. Thus, the self-corrosion potential of the Al-Zn-In alloy added with Er moves positively and the self-corrosion current density decreases.

Table 5. Fitting values of polarization curves.

\begin{tabular}{ccc}
\hline Alloy & $\boldsymbol{E}_{\text {corr }}$ & $\boldsymbol{i}_{\text {corr }}$ \\
\hline $\mathrm{Al}-\mathrm{Zn}-\mathrm{In}$ & $-1098 \mathrm{mV}$ & $10.81 \pm 0.6 \mu \mathrm{A} / \mathrm{cm}^{2}$ \\
$\mathrm{Al}_{3} \mathrm{Er}$ & $-1136 \mathrm{mV}$ & $23.86 \pm 0.8 \mu \mathrm{A} / \mathrm{cm}^{2}$ \\
\hline
\end{tabular}

\subsubsection{AC Impedance of Simulated Alloy}

Figure 15 shows the $\mathrm{AC}$ impedance spectrum of the $\mathrm{Al}_{3} \mathrm{Er}$-simulated alloy and the $\mathrm{Al}-$ $\mathrm{Zn}$-In alloy. The AC impedance spectrum of the Al-Zn-In alloy shows that the dissolution process of the Al-Zn-In alloy is dominated by pitting corrosion. Due to the "dissolutionredeposition" of $\mathrm{Zn}$, In, and other elements in the alloy, the Al-Zn-In alloy is always in the state of active dissolution. Compared with the Al-Zn-In alloy, the Nyquist diagram of the $\mathrm{Al}_{3}$ Er-simulated alloy shows the characteristics of two capacitive resistive arcs. This indicates that an oxide film is formed on the surface of the $\mathrm{Al}_{3} \mathrm{Er}$-simulated alloy during the corrosion process, which is consistent with the characteristics of the polarization curve.

Table 6 shows the fitting results of the impedance data. $R_{\text {sol }}$ represents the resistance value of the solution during the dissolution process. The solution resistances of the two alloys are not quite different. It can be considered that the solution resistance has a limited effect on the dissolution process. $R_{\mathrm{ct}}$ represents the charge transfer resistance between the double electron layers on the alloy surface. The charge transfer resistance of the Al-Zn-In alloy is $684.1 \Omega \cdot \mathrm{cm}^{2}$, the charge transfer resistance of $\mathrm{Al}_{3} \mathrm{Er}$ analog alloy is $177 \Omega \cdot \mathrm{cm}^{2}$, the dissolution rate is higher, and the charge transfer resistance of $\mathrm{Al}_{3}$ Er simulation alloy is much smaller than that of Al-Zn-In alloy, which shows that the charge transfer resistance of the $\mathrm{Al}_{3}$ Er-simulated alloy is less hindered by passing through the interface between 
electrode and electrolyte solution at the same potential. This is consistent with the fitting results of the polarization curve. The smaller the charge transfer resistance, the greater the corrosion current will be. This means that the preferential dissolution of the segregated phase will occur during the dissolution of the $\mathrm{Al}_{3} \mathrm{Er}$ phase in the $\mathrm{Al}-\mathrm{Zn}-\mathrm{In}-\mathrm{Er}$ alloy. $R$ represents the diffusion resistance of pitting corrosion, i.e., the resistance of intermediate products in the dissolution process. The $R$ value of the Al-Zn-In alloy is only $275.6 \Omega \mathrm{cm}^{2}$, while that of the $\mathrm{Al}_{3} \mathrm{Er}$-simulated alloy is as high as $3518 \Omega \mathrm{cm}^{2}$. Combined with the above analysis, the $\mathrm{Al}_{3} \mathrm{Er}$-simulated alloy may form a complete passivation film in the dissolution process, resulting in passivation phenomenon, and the dissolution process is no longer dominated by pitting corrosion, so its $R$ value increases sharply.

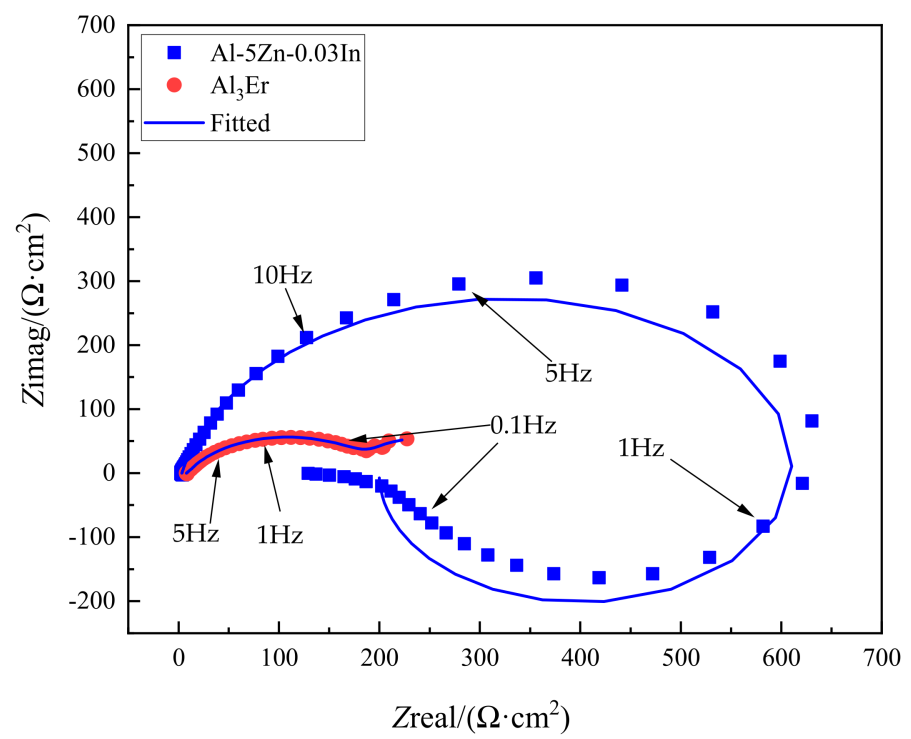

Figure 15. EIS of Al-Zn-In and $\mathrm{Al}_{3}$ Er alloys.

Table 6. Fitting values of EIS.

\begin{tabular}{ccccccc}
\hline Alloy & $\boldsymbol{R}_{\text {sol }}\left(\boldsymbol{\Omega} \cdot \mathbf{c m}^{\mathbf{2}}\right)$ & $\boldsymbol{R}_{\mathrm{ct}}\left(\boldsymbol{\Omega} \cdot \mathbf{c m}^{\mathbf{2}}\right)$ & $\boldsymbol{Q}\left(\boldsymbol{\Omega}^{-\mathbf{1} \cdot \mathbf{c m}} \mathbf{2}^{-\mathbf{2}} \mathbf{s}^{-\mathbf{1}}\right)$ & $\boldsymbol{n}$ & $\boldsymbol{R}\left(\boldsymbol{\Omega} \cdot \mathbf{c m}^{2}\right)$ & $\chi^{\mathbf{2} *}$ \\
\hline $\mathrm{Al}-\mathrm{Zn}-\mathrm{In}$ & $3.35( \pm 0.16)$ & $684.1( \pm 114)$ & $9.147( \pm 1.1) \times 10^{-5}$ & 0.8734 & $275.6( \pm 28.9)$ & $10.85 \times 10^{-3}$ \\
$\mathrm{Al}_{3} \mathrm{Er}$ & $4.47( \pm 0.05)$ & $177( \pm 9.36)$ & $222.3( \pm 7.95) \times 10^{-5}$ & 0.6605 & $3518( \pm 598)$ & $1.58 \times 10^{-3}$ \\
\hline
\end{tabular}

* Total Error $<15 \%$.

\section{Conclusions}

In this paper, the microstructure of the Al-5Zn-0.03In- $x$ Er alloy was observed, and the composition of physical phase and segregation phase was detected. The electrochemical properties of the Al-5Zn-0.03In- $x \mathrm{Er}$ alloy and the segregation phase simulation alloy were tested by polarization curve and electrochemical impedance. The conclusions are as follows.

1. With the increase in Er content, the structure is refined, gradually transitioning from coarse dendrites to fine dendrites. The alloy structure is mainly composed of Al- $\mathrm{Zn}$ solid solution and Al3Er precipitated phase.

2. With the addition of Er element, the self-corrosion potential of the alloy moved positively, the potential difference between Al-5Zn-0.03In and Al-5Zn-0.03In-1Er reaches $119.1 \mathrm{mV}$, the self-corrosion current density decreases, and the corrosion resistance increases.

3. The electrochemical impedance spectra of the alloy were fitted by the equivalent cir cuit Rsol (QRct (LR)). The dissolution process of the anode is first caused by pitting corrosion, and the anode can be activated and dissolved continuously through the "dissolution re-deposition" process. The impedance of the alloy increased with the 
increase of Er content, and the corrosion resistance increases, which was consistent with the polarization curve.

4. When Er content is less than $1 \mathrm{wt} . \%$, the refinement of microstructure improved the dissolution state of the Al-5Zn-0.03In-xEr alloy, and increased the current efficiency of the Al-5Zn-0.03In-xEr alloy. When Er content is more than $1 \mathrm{wt} . \%$, a large number preferentially dissolve and fall off in the segregation phase, resulting in the loss of current efficiency. The right amount of Er in Al-Zn-In alloy is $1 \mathrm{wt} . \%$.

5. Compared with the Al-Zn-In alloy, the self-corrosion potential of simulated segregation phase $\mathrm{Al} 3 \mathrm{Er}$ has a negative shift of $38 \mathrm{mV}$, and the self-corrosion current density increases by $13.05 \mu \mathrm{A} / \mathrm{cm}^{2}$. The passivation phenomenon occurred during the experiment, which inhibited the further activation of the dissolution reaction of the Al-Zn-In-Er alloy to some extent.

Author Contributions: Conceptualization, M.Y. and Z.X.; software, M.Y.; validation, Z.X., J.C. and Z.T.; formal analysis, J.C.; investigation, M.Y., X.C.; resources, Z.X.; data curation, M.Y.; writingoriginal draft preparation, M.Y., Z.S.; writing—review and editing, M.Y., Z.X.; funding acquisition, Z.X., J.Z.; All authors have read and agreed to the published version of the manuscript.

Funding: This research was funded by Natural Science Foundation of China (Grant No. 51961008), the Regional Joint Fund of National Natural Science Foundation of China (U20A20276) and Guangxi Natural Science Foundation (2020GXNSFAA297269).

Institutional Review Board Statement: Not applicable.

Informed Consent Statement: Not applicable.

Data Availability Statement: Data supporting reported results can be found in this paper.

Acknowledgments: The authors are grateful to our former group members Zinan Shen and Xiaoyang Chen for the electrochemical measurement and analysis discussion.

Conflicts of Interest: The authors declare no conflict of interest.

\section{References}

1. Sina, H.; Emamy, M.; Saremi, M.; Keyvani, A.; Mahta, M.; Campbell, J. The influence of Ti and Zr on electrochemical properties of aluminum sacrificial anodes. Mater. Sci. Eng. A 2006, 431, 263-276. [CrossRef]

2. Saeri, M.R.; Keyvani, A. Optimization of Manganese and Magnesium Contents in As-cast Aluminum-Zinc-Indium Alloy as Sacrificial Anode. J. Mater. Sci. Technol. 2011, 27, 785-792. [CrossRef]

3. Tang, D.; Du, Y.; Li, X.; Liang, Y.; Lu, M. Effect of alternating current on the performance of magnesium sacrificial anode. Mater Des. 2016, 93, 133-145. [CrossRef]

4. El Abedin, S.Z.; Endres, F. Electrochemical behaviour of Al and some of its alloys in chloride solutions. In Passivation of Metals and Semiconductors, and Properties of Thin Oxide Layers; Elsevier: Amsterdam, The Netherlands, 2006; pp. $633-638$.

5. Pathak, S.S.; Mendon, S.K.; Blanton, M.D.; Rawlins, J.W. Magnesium-Based Sacrificial Anode Cathodic Protection Coatings (Mg-Rich Primers) for Aluminum Alloys. Metals 2012, 2, 353-376. [CrossRef]

6. Feng, X.; Yan, Q.; Lu, X.; Wu, T.; Zhang, Y.; Zuo, Y.; Wang, J. Protection performance of the submerged sacrificial anode on the steel reinforcement in the conductive carbon fiber mortar column in splash zones of marine environments. Corros. Sci. 2020, 174, 108818. [CrossRef]

7. Shibli, S.M.A.; Jabeera, B.; Manu, R. Development of high performance aluminium alloy sacrificial anodes reinforced with metal oxides. Mater. Lett. 2007, 61, 3000-3004. [CrossRef]

8. Xiong, W.; Qi, G.T.; Guo, X.P.; Lu, Z.L. Anodic dissolution of Al sacrificial anodes in $\mathrm{NaCl}$ solution containing Ce. Corros. Sci. 2011, 53, 1298-1303. [CrossRef]

9. Munoz, A.G.; Saidman, S.B.; Bessone, J.B. Corrosion of an Al-Zn-In alloy in chloride media. Corros. Sci. 2002, 44, 2171-2182. [CrossRef]

10. Salinas, D.R.; Bessone, J.B. Electrochemical Behavior of Al-5\%Zn-0.1\%Sn Sacrificial Anode in Aggressive Media: Influence of Its Alloying Elements and the Solidification Structure. Corrosion 2012, 47, 665-674. [CrossRef]

11. Shayeb, H.A.E.; Wahab, F.M.A.E.; Abedin, S.Z.E. Electrochemical behaviour of Al, Al-Sn, Al-Zn and Al-Zn-Sn alloys in chloride solutions containing indium ions. J. Appl. Electrochem. 2001, 43, 655-669.

12. Muñoz, A.G.; Saidman, S.B.; Bessone, J.B. Corrosion mechanism of Al-Zn-In alloys in chloride solutions. Investig. Apl. Latinoam. 2003, 33, 275-280.

13. Nie, Z.R.; Jin, T.; Fu, J.; Xu, G.; Yang, J.; Zhou, J.X.; Zuo, T.Y. Research on Rare Earth in Aluminum. Mater. Sci. Forum 2002, 1731, 396-402. [CrossRef] 
14. Kong, W.B.; Li, X.X.; Hu, X.P. Effects of RE Micro-Alloying Additions on the Corrosion Behavior of an Al-Mg-Si Alloy. Key Eng. Mater. 2017, 729, 40-45. [CrossRef]

15. Majeed, F.S.A.; Bin Mohd Yusof, N.; Azlan Suhaimi, M.; Bin Ahmad, R.; Basher Asmael, M.; Sallehuddin Bin Yusof, M. Outcome of mix Ce and Er addition on solidification microstructure of the LM25 (Al-7Si-alloy). Mater. Today Proc. 2021, 39, 935-940. [CrossRef]

16. Pan, S.; Chen, X.; Zhou, X.; Wang, Z.; Chen, K.; Cao, Y.; Lu, F.; Li, S. Micro-alloying effect of Er and Zr on microstructural evolution and yield strength of Al-3Cu (wt.\%) binary alloys. Mater. Sci. Eng. A 2020, 790, 139391. [CrossRef]

17. Wang, Y.; Zhang, S.; Wu, R.; Turakhodjaev, N.; Hou, L.; Zhang, J.; Betsofen, S. Coarsening kinetics and strengthening mechanisms of core-shell nanoscale precipitates in Al-Li-Yb-Er-Sc-Zr alloy. J. Mater. Sci. Technol. 2021, 61, 197-203. [CrossRef]

18. Colombo, M.; Albu, M.; Gariboldi, E.; Hofer, F. Microstructural changes induced by Er and Zr additions to A356 alloy investigated by thermal analyses and STEM observations. Mater. Charact. 2020, 161, 110117. [CrossRef]

19. Vo, N.Q.; Dunand, D.C.; Seidman, D.N. Improving aging and creep resistance in a dilute Al-Sc alloy by microalloying with Si, Zr and Er. Acta Mater. 2014, 63, 73-85. [CrossRef]

20. Liu, L.; Jiang, J.-T.; Cui, X.-Y.; Zhang, B.; Zhen, L.; Ringer, S.P. Correlation between precipitates evolution and mechanical properties of Al-Sc-Zr alloy with Er additions. J. Mater. Sci. Technol. 2022, 99, 61-72. [CrossRef]

21. Ma, J.; Wen, J. The effects of lanthanum on microstructure and electrochemical properties of Al-Zn-In based sacrificial anode alloys. Corros. Sci. 2009, 51, 2115-2119. [CrossRef]

22. Torre, A.; Pérez-Bustamante, R.; Camarillo-Cisneros, J.; Gómez-Esparza, C.; Medrano-Prieto, H.M.; Martínez-Sánchez, R. Mechanical properties of the A356 aluminum alloy modified with La/Ce. J. Rare Earths 2013, 31, 811-816. [CrossRef]

23. Ma, J.; Wen, J.; Zhai, W.; Li, Q.J.M.C. In situ corrosion analysis of Al-Zn-In-Mg-Ti-Ce sacrificial anode alloy. Mater. Charact. 2012, 65, 86-92. [CrossRef]

24. Nie, Z.R.; Li, B.L.; Wang, W.; Jin, T.N.; Zuo, T.Y. Study on the Erbium Strengthened Aluminum Alloy. Mater. Sci. Fourm 2007, 623, 546-549.

25. She, X.; Jiang, X.; Qi, B.; Chen, K. Effect of Er on Microstructure and Mechanical Properties of 5052 Aluminum Alloy with Big Width-To-Thickness Ratio. Materials 2020, 13, 568. [CrossRef] [PubMed]

26. Bai, S.; Huang, T.; Xu, H.; Liu, Z.; Wang, J.; Yi, X. Effects of small Er addition on the microstructural evolution and strength properties of an Al-Cu-Mg-Ag alloy aged at $200{ }^{\circ}$ C. Mater. Sci. Eng. A 2019, 766, 138351. [CrossRef]

27. Venugopal, A.; Angal, R.D.; Raja, V.S. Effect of Grain-Boundary Corrosion on Impedance Characteristics of an Aluminum-ZincIndium Alloy in 3.5\% Sodium Chloride Solution. Corrosion 1996, 52, 138-142. [CrossRef]

28. Salinas, D.R.; García, S.G.; Bessone, J.B. Influence of alloying elements and microstructure on aluminium sacrificial anode performance: Case of Al-Zn. J. Appl. Electrochem. 1999, 29, 1063-1071. [CrossRef]

29. Hang, L.; Bing, W.; Zhengbing, X.; Jianmin, Z.; Rong, C.; Heng, L.; Yanyan, L. Effect of Er on Microstructure and Electrochemical Performance of Al-Zn-In Anode. Rare Met. Mater. Eng. 2016, 45, 1848-1854.

30. Shen, Z.; Chen, X.; Li, H.; Xu, Z.; Zeng, J. Effect of Er Content on the Microstructure and Current Efficiency of Al-Zn-In- $x$ Er Alloy. Foundry Technol. 2018, 39, 765-768.

31. Osório, W.R.; Freitas, E.S.; Garcia, A. EIS and potentiodynamic polarization studies on immiscible monotectic Al-In alloys. Electrochim. Acta. 2013, 102, 436-445. [CrossRef]

32. Osório, W.R.; Peixoto, L.C.; Moutinho, D.J.; Gomes, L.G.; Ferreira, I.L.; Garcia, A. Corrosion resistance of directionally solidified Al-6Cu-1Si and Al-8Cu-3Si alloys castings. Mater. Design 2011, 32, 3832-3837. [CrossRef]

33. Zhang, X.L.; Jiang, Z.H.; Yao, Z.P.; Song, Y.; Wu, Z.D. Effects of scan rate on the potentiodynamic polarization curve obtained to determine the Tafel slopes and corrosion current density. Corros. Sci. 2009, 51, 581-587. [CrossRef]

34. McCafferty, E. Validation of corrosion rates measured by the Tafel extrapolation method. Corros. Sci. 2005, 47, 3202-3215. [CrossRef]

35. Zahra, A.; Zahra, C.Y.; Ciach, R. Contribution to the study of the Al-Zn phase diagram. J. Therm. Anal. 1983, 26, 303-307. [CrossRef]

36. Okamoto, H. Al-Er (Aluminum-Erbium). J. Phase Equilibria Diffus. 2011, 32, 261-262. [CrossRef]

37. Wang, Y.; Wu, X.; Cao, L.; Tong, X.; Couper, M.J.; Liu, Q. Effect of trace Er on the microstructure and properties of Al-Zn-Mg-CuZr alloys during heat treatments. Mater. Sci. Eng. A 2020, 792, 139807. [CrossRef]

38. Nie, Z.R.; Wen, S.P.; Huang, H.; Li, B.L.; Zuo, T.Y. Research progress of Er-containing aluminum alloy. Chin. J. Nonferrons Met. 2011, 21, 2361-2370.

39. Guo, W.C.; Chen, X.H.; Liu, P.; Yu, G.L.; Fu, S.L.; Fan, J.; Zhou, H.L.; Liu, H. Effects of Er Additions on the Microstructure, Mechanical Properties, and Electrical Conductivity of the Al-0.4Fe-0.05Si Alloy. Adv. Eng. Mater. 2020, 23, 2000955. [CrossRef]

40. Karnesky, R.A.; Dunand, D.C.; Seidman, D.N. Evolution of nanoscale precipitates in Al microalloyed with Sc and Er. Acta Mater. 2009, 57, 4022-4031. [CrossRef]

41. Ma, J.L.; Wen, J.B.; Lu, X.W.; Li, Y.Z. Electrochemical impedance spectroscopy of aluminum alloy anode during corrosion process. Corros. Prot. 2009, 30, 373-376.

42. Ma, J.L.; Wen, J.B.; Li, G.F.; Jiao, M.W. Study on aluminum alloy containing manganese element sacrificial anode material. Heat Treat. Met. 2008, 33, 57-60. 
43. Liu, Q.; Ma, Q.X.; Chen, G.Q.; Cao, X.; Zhang, S.; Pan, J.L.; Zhang, G.; Shi, Q.Y. Enhanced corrosion resistance of AZ91 magnesium alloy through refinement and homogenization of surface microstructure by friction stir processing. Corros. Sci. 2018, 138, 284-296. [CrossRef]

44. Bastidas, J.M.; Polo, J.; Torres, C.; Cano, E. A study on the stability of AISI 316L stainless steel pitting corrosion through its transfer function. Corros. Sci. 2001, 43, 269-281. [CrossRef]

45. Mohazzab, B.F.; Jaleh, B.; Fattah-alhosseini, A.; Mahmoudi, F.; Momeni, A. Laser surface treatment of pure titanium: Microstructural analysis, wear properties, and corrosion behavior of titanium carbide coatings in Hank's physiological solution. Surf. Interfaces 2020, 20, 100597. [CrossRef]

46. Reboul, M.C.; Gimenez, P.; Rameau, J.J. A Proposed Activation Mechanism for Al Anodes. Corrosion 2012, 40, 366-371. [CrossRef] 